\title{
Tulane
}

Tulane Economics Working Paper Series

\section{Environmental Enforcement and Compliance: Lessons from Pollution, Safety, and Tax Settings}

\author{
James Alm \\ Department of Economics \\ Tulane University \\ jalm@tulane.edu
}

\author{
Jay Shimshack \\ Frank Batten School of \\ Leadership and Public Policy \\ University of Virginia \\ jay.shimshack@virginia.edu
}

Working Paper 1409

October 2014

\begin{abstract}
Environmental monitoring and enforcement are controversial and incompletely understood. This survey reviews what we do and do not know about the overall effectiveness, as well as the cost effectiveness, of pollution monitoring and enforcement. We ask five key questions: What do environmental monitoring and enforcement actions look like in the real world? How do we assess environmental compliance and deterrence? Do environmental monitoring and enforcement actions get results? How, why, and when do inspections and sanctions achieve compliance and reduce pollution? And, what do the answers to the preceding questions tell us about designing and implementing more effective and more cost effective public policies for the environment? A key contribution is drawing lessons from diverse sources, including insights from theoretical, empirical, and experimental contributions in environmental, tax, and safety settings. We conclude that traditional environmental monitoring and enforcement actions generate important deterrence effects. However, there are limits to such deterrence, and deterrence itself cannot fully explain all patterns of environmental behavior. Encouraging compliance requires both traditional tools and additional tools.
\end{abstract}

Keywords: environmental economics, enforcement and compliance JEL codes: Q50, Q58, K32, H26 


\title{
Environmental Enforcement and Compliance: Lessons from Pollution, Safety, and Tax
} Settings

James Alm, Tulane University, Department of Economics, 206 Tilton Hall, New Orleans, LA 70118 USA; jalm@tulane.edu

Jay Shimshack, University of Virginia, Frank Batten School of Leadership and Public Policy,206 Tilton Hall, New Orleans, LA 70118 USA; jshimsha@tulane.edu

\begin{abstract}
Environmental monitoring and enforcement are controversial and incompletely understood. This survey reviews what we do and do not know about the overall effectiveness, as well as the cost effectiveness, of pollution monitoring and enforcement. We ask five key questions: What do environmental monitoring and enforcement actions look like in the real world? How do we assess environmental compliance and deterrence? Do environmental monitoring and enforcement actions get results? How, why, and when do inspections and sanctions achieve compliance and reduce pollution? And, what do the answers to the preceding questions tell us about designing and implementing more effective and more cost effective public policies for the environment? A key contribution is drawing lessons from diverse sources, including insights from theoretical, empirical, and experimental contributions in environmental, tax, and safety settings. We conclude that traditional environmental monitoring and enforcement actions generate important deterrence effects. However, there are limits to such deterrence, and deterrence itself cannot fully explain all patterns of environmental behavior. Encouraging compliance requires both traditional tools and additional tools.
\end{abstract}

\section{Introduction}

Policymakers commonly argue that regulations require regular monitoring and enforcement. Scholars have considered the general subject of the public enforcement of law since at least Bentham (1789). Local, state, and federal authorities spend billions of dollars annually on inspections and sanctions in a wide range of regulatory and other settings.

Nevertheless, the overall effectiveness and the cost effectiveness of environmental monitoring and enforcement are controversial and incompletely understood. Many observers believe that rigorously enforced regulations explain dramatic reductions in point source emissions of conventional air, water, and waste pollution over the past four decades. ${ }^{1}$ Still, stakeholders frequently push for reductions in the frequency and intensity of environmental oversight. For example, members of the U.S. Congress pushed for reduced overall pollution enforcement during the early 1990s (Mintz 2012). The U.S. Environmental Protection Agency (EPA) itself recently proposed a strategic plan that involved substantive cuts in inspections and sanction

\footnotetext{
${ }^{1}$ See, for example, relevant qualitative survey results of Kagan et al. (2003), Khanna and Anton (2002), Doonan et al. (2005), and Delmas and Toffel (2008).
} 
numbers (USEPA 2014). Environmental economists most often just assume compliance in their models and regularly ignore the role of monitoring and enforcement in regulatory design and implementation (Cropper and Oates 1992). Scholars who do consider pollution monitoring and enforcement often increasingly spurn traditional instruments in favor of more novel cooperative, voluntary, and information dissemination approaches.

This survey reviews what economists do and do not know about the effectiveness, as well as the cost effectiveness, of pollution monitoring and enforcement. We focus mainly on lessons for and from the U.S. policy environment, but we also discuss especially important research findings from international settings as well. We draw most of our insights from a subjective assessment of the existing theoretical, experimental, and empirical environmental economics literature. However, where appropriate and helpful, we also draw lessons from criminal, tax compliance, and occupational health and safety settings. We examine the criminal literature because the historical law and economic foundations of the environmental enforcement literature were developed in this context. We consider the tax context because the availability of data have generated an especially rich and diverse theoretical, empirical, and experimental literature, a literature that has also been often applied to environmental compliance. We draw on the health and safety literature because the Occupational Safety and Health Administration (OSHA) and the EPA have similarly broad regulatory authority and often share institutional features. Moreover, comparisons between safety and environmental regulation are made in the extant literature (e.g., Deily and Gray 2007). We do not investigate enforcement and compliance lessons from other settings like food safety, nuclear safety, and health care fraud, although we acknowledge that examining parallels between these contexts and the environmental context represents promising future research.

Our present focus is on five questions: What do environmental monitoring and enforcement actions look like in the real world? How do we assess environmental compliance and deterrence? Do environmental monitoring and enforcement actions get results? How, why, and when do inspections and sanctions achieve compliance and reduce pollution? And, what do the answers to the preceding questions tell us about designing and implementing more effective and more cost effective public policies for the environment?

We begin in the next section by reviewing key institutions. Section 3 discusses measuring environmental performance and compliance, paying particular attention to the perils and promise of assessing compliance in the presence of self-reported pollution. Section 4 summarizes how inspections and sanctions might influence compliance and Section 5 reviews the existing evidence on the deterrence effects of environmental monitoring and enforcement. Section 6 investigates lessons from occupational safety and tax compliance settings. We explore mechanisms and motivations for compliance in Section 7, focusing on both rational-actor models and more recent socio-behavioral models. Section 8 highlights key lessons for policy, and Section 9 briefly concludes with directions for future research. 
This review extends surveys by Cohen (1999), Heyes (2000), Gray and Shimshack (2011), Stranlund (2013), and Shimshack (2014). Key insights from law and economic, tax compliance, and occupational safety literatures draw frequently from Polinsky and Shavell (2000), Alm (2012), and Leeth (2012). This monograph excludes some issues. Most notably, we do not survey the large literature on optimal enforcement theory, nor do we review the many attempts to explain divergences between real world regulator behavior and optimal regulator behavior. We refer the interested reader to Polinsky and Shavell (2000), Shavell (2004), Cohen (1999), Heyes (2000), and Shimshack (2014).

\section{The United States approach to monitoring and enforcement ${ }^{2}$}

\subsection{Authority}

What do environmental monitoring and enforcement actions look like in the real world? In truth, environmental monitoring and enforcement in the United States are governed by a bewildering array of state and federal statutes and agencies. Statutes include the Clean Air Act (CAA), the Clean Water Act (CWA), the Resource Conservation and Recovery Act (RCRA), the Comprehensive Environmental Response, Compensation and Liability Act (CERCLA, or Superfund), the Toxic Substances Control Act (TSCA), the National Environmental Policy Act (NEPA), the Oil Pollution Act (OPA), the Federal Insecticide, Fungicide, and Rodenticide Act (FIFRA), and the Emergency Planning and Community Right to Know Act (EPCRA). At the federal level, the EPA Office of Enforcement and Compliance Assurance and 10 regional offices monitor compliance and levy enforcement actions for noncompliance with air, water, toxics, and waste pollution regulations. Other federal EPA offices, such as the Office of Administration and Policy, the Office of Civil Enforcement, the Office of Criminal Enforcement, Forensics, and Training, and the Office of Compliance develop guidelines, prosecute civil and criminal cases, and evaluate pollution program effectiveness. The EPA regularly refers especially significant civil and criminal cases to the Department of Justice. Other federal agencies, such as the Food and Drug Administration, the Coast Guard, and the Department of Agriculture, also oversee environmental monitoring and enforcement programs.

Outside of administrative agencies, federal oversight of environmental monitoring and enforcement is largely indirect. The executive branch appoints key EPA personnel, including the Administrator, Deputy Administrators, and the Assistant Administrator for Enforcement and Compliance Assurance. The legislative branch passes overarching statutes, determines agency budgets, approves executive nominees, holds environmental enforcement hearings, and occasionally advocates for changes in overall monitoring and enforcement intensity. As a general rule, however, neither legislators nor members of the executive branch become directly involved in specific enforcement actions. See Mintz (2012) and Bressman and Vandenbergh (2006) for discussion, including a review of notable exceptions.

\footnotetext{
${ }^{2}$ This section shares features with institutional discussions in Gray and Shimshack (2011) and Shimshack (2014).
} 
Despite oversight and final authority at the federal and regional level, primary monitoring and enforcement activities under most environmental programs are delegated. State, local, and tribal agencies maintain enforcement primacy under major environmental statutes unless they decline the opportunity, unless the regional or federal EPA determines enforcement oversight is inadequate, or unless the EPA concludes that the potential for environmental harm is unusually great. Under the major environmental statutes, federal primacy is uncommon for entire states or tribes but more common for specific facilities with a given state or tribal area. Regional and federal EPA offices do retain widespread primacy for many of the more minor environmental statutes. Nevertheless, nearly all actual environmental monitoring and enforcement actions are undertaken by state offices of environmental protection.

\subsection{Instruments}

Formal environmental monitoring takes two key forms: self-reporting and authority monitoring. For most large facilities regulated under the major environmental statutes, regulated entities selfreport their pollution emissions and/or compliance status on a regular basis. Self-reports can be regular snapshots or longer-term summaries of emissions and compliance. Continuous emissions monitoring systems are common in the electric utility sector, and serve a similar purpose to selfreporting, although measurements and reporting are automated. In many settings, authority monitoring primarily serves to verify the accuracy of self-reports. In settings without extensive self-reporting, however, authority monitoring serves as the primary oversight tool. Monitoring by responsible authorities may involve general reconnaissance and broad evaluations of environmental quality with events or anomalies subsequently traced back to responsible sources. More commonly under the major pollution statutes, agency monitoring involves on-site inspections. Inspections vary significantly in scope and scale, ranging from quick visual inspections of effluents to full scale evaluations when regulators observe equipment operation and maintenance, track self-reporting procedures and sampling, and conduct their own effluent sampling. Inspections may last less than one day to several weeks.

Inspection targeting varies by statute, regulatory program, authority, industry, and time period. By law, regulators are advised to conduct inspections 'for cause' or following 'neutral selection'. Regulators conduct 'for cause' inspections in response to citizen complaints, employee complaints, other direct evidence of possible violation, compliance history, or the potential for significant environmental harm. Environmental justice considerations and proximity to vulnerable communities are increasingly used as 'for cause' targeting justifications. Regulators conduct 'neutral selection' inspections based on regulator cost factors like proximity to other facilities being inspected and time since last inspection. Non-binding statutory guidelines advise regulators to inspect large CAA and CWA facilities every two years and medium-sized CAA and CWA facilities every five years, so time since last inspection is often the most significant determinant of inspection probabilities under 'neutral selection.' Under virtually all major environmental programs, facilities are notified in advance of authorities' intent to inspect. Also, 
purely random inspections are typically not conducted under 'neutral selection' or 'for cause' targeting principles and are therefore rare.

When pollution violations are self-reported or uncovered during regulator inspections, authorities may pursue one or more enforcement actions. Informal enforcement actions include warning letters, telephone calls, and informal notices of violation. These sanctions are almost always levied by the enforcement authority with primary oversight responsibility (typically, the state). More formal enforcement actions include formal notices of noncompliance and administrative consent orders requiring a return to compliance. Administrative consent orders may be accompanied by financial penalties and/or may require costly supplemental environmental projects. Although some authorities may issue on-site field citations, most financial penalties are issued by state, regional, and federal administrative law judges. State, regional, and federal authorities may also prosecute civil enforcement cases for severe environmental violations or extended noncompliance. Willful violations, violations causing excessive environmental damages, deliberate falsification of environmental records, and attempts to operate outside of the regulatory environment may result in referrals to the Department of Justice or state attorneys general for criminal prosecution (Uhlmann 2009).

Due to limited resources, regulatory complexity, and imprecise statutory requirements, regulators at all levels of authority have significant discretion over monitoring and enforcement intensity (Mintz 2012; Shimshack 2014). Non-binding enforcement guidelines suggest that sanction frequency and severity should be a function of harm, economic gain from violation, offense history, and intent. The strength of the regulator's evidence, fairness, and the violating facility's ability are other important sanction determinants. As a general rule, both enforcement guidelines and enforcement practice strongly favor the least stringent sanction necessary to encourage future compliance. Many significant violations are not associated with any formal enforcement action. Moreover, administrative penalties are far more common than civil or criminal prosecutions, and penalties are typically very low relative to statutory maximums (Gray and Shimshack 2011; Mintz 2012; Shimshack 2014).

Enforcement action information is publicly accessible. Enforcement databases track inspections and sanctions, and industry groups, community organizations, and journalists regularly summarize and disseminate state and federal environmental activity. State, regional, and federal authorities also regularly issue press releases designed to leverage market and non-regulatory legal forces to increase deterrence effects of public actions. Channels may include pressures from investors, employees, community activists, supply chains, and consumers (Shimshack 2013).

\subsection{Public activities}

The regulated universe for U.S. environmental monitoring and enforcement exceeds 40 million facilities. However, the large majority of pollution monitoring and enforcement activity is devoted to approximately 20,000 large CAA major facilities, 20,000 midsize CAA synthetic 
minor facilities, 7,000 large CWA major facilities, 30,000 RCRA large quantity hazardous waste generators, 2,000 RCRA hazardous waste storage and treatment facilities, and 50,000 large SDWA drinking water systems (USEPA 1989, USEPA 2001). Facilities regulated under nearly all statutes and programs vary substantially in terms of industrial composition, ownership structure, and other characteristics. Although the majority of large CAA and RCRA facilities are privately owned, the majority of large CWA and SDWA facilities are publicly owned municipal wastewater treatment plants and community water systems.

Historic variability in federal EPA monitoring and enforcement resources and activities is reasonably well documented. ${ }^{3}$ Real budget allocations for EPA enforcement and compliance assurance declined steadily from about $\$ 690$ million (2013 dollars) in 1994 to approximately $\$ 620$ million (2013 dollars) in 1999. Budgets remained relatively constant in real terms between 1999 and 2013. Enforcement and compliance assurance staffing levels experienced similar steady declines during the 1990s followed by relative stability during the 2000s (Gray and Shimshack 2011).

Historic variation in federal and regional inspections, sanctions, and enforcement cases is also well understood. Federal and regional inspection numbers increased between 1994 and 1998 to a peak of about 23,000 inspections per year, and have since fluctuated between roughly 18,000 and 22,000 annually. Federal and regional administrative penalty numbers have remained relatively stable under the major pollution statutes at around 1,600 to 2,000 per year. Mean administrative penalties across all EPA programs are less than \$20,000, and median administrative penalties across all programs are less than $\$ 10,000$ (Gray and Shimshack 2011; Shimshack 2014). During the 1990s, EPA regional and federal offices referred about 300 to 400 civil cases and 400 to 500 criminal cases to the Department of Justice (DOJ) for prosecution. Referral numbers have trended downward over time, and in the 2000s EPA regional and federal offices referred about 200-300 civil cases and 300-400 criminal cases to the DOJ. ${ }^{4}$ Penalties from civil and criminal cases can be large. For example, in 2011 the Tennessee Valley Authority agreed to resolve CAA violations by investing $\$ 350$ million in supplemental environmental projects, and an agricultural corporation paid a $\$ 1.9$ million penalty for CWA violations at egg production facilities in Texas and Oklahoma.

Although activities and trends at the federal and regional level are well documented, historic spatial and temporal variability in monitoring and enforcement at the state or local level is poorly documented and poorly understood. Anecdotal estimates suggest that total annual state monitoring and enforcement expenditures are of roughly similar magnitude to total annual regional and federal expenditures. National enforcement databases like the EPA's Enforcement and Compliance History Online database (ECHO) do suggest that monitoring and enforcement

\footnotetext{
${ }^{3}$ EPA budget summaries are available online at: http://www2.epa.gov/planandbudget/archive\#BudgetSummary .

${ }^{4}$ EPA national enforcement summaries are available at: http://cfpub.epa.gov/compliance/resources/reports/nets/.
} 
intensity under any given statute at any given point in time varies quite significantly across states (Shimshack 2014). However, recordkeeping, data management, industrial composition, facility characteristics, and many other factors at least partially explain enforcement differences across states. Spatial heterogeneity cannot necessarily be attributed to differences in enforcement resources and regulatory stringency.

Despite notable heterogeneity in implementation and intensity across states, localities, statutes, industries, and even facilities, the broadest regulatory approach to environmental monitoring and enforcement has remained similar for at least two decades. Due to persistent budget pressures and technological advances, however, significant changes in environmental monitoring and enforcement may soon be afoot. The EPA's 2014 to 2018 strategic plan calls for significant reductions in the overall number of traditional inspections and enforcement actions (USEPA 2014). The EPA intends to increase its focus on repeat offenders and the most significant violators. Specific objectives are further articulated in a regulatory program dubbed 'next generation environmental compliance'. The key features of next generation environmental compliance include settings where compliance is the default, advanced pollution monitoring technologies, automatic electronic reporting of pollution emissions, increased transparency of compliance and performance, and innovative public enforcement strategies such as partnerships with private third-party certifiers (Giles 2013).

\subsection{Private enforcement}

Every major environmental statute, including the CAA, the CWA, the RCRA, the EPCRA, and the SDWA, allows formal private enforcement. Here, citizen groups sue specific facilities or the primary regulatory agency to force a return to compliance and to seek penalties for noncompliance (Naysnerski and Tietenberg 1992; Langpap and Shimshack 2010). In practice, most recent private enforcement is conducted on behalf of citizens by local legal groups or by local chapters of large legal organizations like Waterkeeper Alliance. Citizen cases directly targeting polluting facilities are typically only allowed when the public agencies fail to issue their own enforcement actions or when public agencies issue adequate enforcement actions to ensure a return to compliance. Private citizen suits are also typically proceeded by a 60 -day notice period during which the public regulator has the opportunity to intervene to preempt the private suit.

Despite widespread authorization, and despite policy observers referring to citizen prosecutions as 'the most pervasive, prominent, and continuing innovation in the modern environmental era' (Thompson 2000), formal private enforcement is only relatively common under the CWA. Approximately 50-150 CWA citizen suits are initiated in federal district or circuit courts each year (Smith 2004). However, less formal citizen monitoring in which community organizations inform regulators of possible violations and work with facilities to improve compliance is common under all statutes. Grant and Grooms (2012) and Grant and Langpap (2013) discuss the causes and consequences of such private monitoring in a water pollution context. 


\section{Assessing compliance}

\subsection{Metrics for measuring compliance}

How do we assess environmental compliance? First, note that assessing environmental compliance is complex. Many facilities are simultaneously regulated under several statutes and programs. Nearly all statutes regulate several pollutants, and large facilities may be responsible for complying with limits for dozens of pollutants simultaneously under a single regulatory program. Individual pollutants may be subject to quantity and/or concentration limits, and regulations may specify maximum limits and/or average limits. Even for the same facility and the same regulatory program, different pollutants may be regulated over several different compliance periods. For example, some pollutants may be subject to monthly limits while others are subject to quarterly or annual limits. Pollution violations may be minor or may be associated with significant environmental harm relative to the status quo.

In addition to effluent violations, facilities may be out of compliance for scheduling or procedural violations. Such violations often entail failure to submit self-reports or required paperwork in a timely fashion. Incomplete self-reporting may also constitute a violation. Other types of violations may include inadequate equipment installation, poor equipment maintenance, failure to meet milestone obligations under a consent decree, and recordkeeping violations.

As a result of regulatory complexity, stakeholders must carefully interpret metrics for evaluating and reporting compliance or noncompliance. ${ }^{5}$ An especially common, but easily misinterpreted, noncompliance metric is an aggregate binary noncompliance indicator. Here, a 0/1 variable designates the presence of a violation of any type for a given period of time. More detailed noncompliance indicators may identify the presence of a violation of a specific type or may indicate a violation for a specific pollutant during a given period of time. For example, the EPA designates some violations as significant or high priority if the violation generates the potential for considerable environmental harm or signals a repeated pattern of noncompliance. Researchers often code effluent violations for single pollutants as noncompliance if emissions exceed permitted levels by any amount for a given monitoring period, such as a month. Other noncompliance metrics include noncompliance indexes, where variables represent the number of violations of various types for a given period. Duration-based measures signify the number of months or quarters in violation over a longer period of time. Noncompliance may also be characterized by emissions ratios, where actual emissions for a given pollutant are expressed as a percentage of permitted levels for that pollutant.

It is important to recognize that different noncompliance metrics can generate vastly different representations of compliance at any given point in time. Even for a given industry, facility, and/or program, noncompliance for a single pollutant may be low while noncompliance across all pollutants may be high. Noncompliance determined by purely effluent violations may be low

\footnotetext{
${ }^{5}$ For a more complete comparison of noncompliance metrics, see Shimshack (2009).
} 
while noncompliance metrics that include scheduling, reporting, and procedural violations may be high. For these and other reasons, regulators, researchers, and other stakeholders must be careful not to over-interpret any static noncompliance indicator in isolation. A given metric is most useful when compared with the same metric applied at another point in space or time; that is, although different compliance metrics have different strengths and weakness, a given compliance metric is most meaningful when used to measure changes or trends over time, to compare different facilities or industries at the same point in time, or to evaluate the impact of shocks or policy interventions.

\subsection{Measuring compliance with self-reported data}

Self-monitoring in environmental contexts is common. With an administrative universe spanning over 40 million entities regulated under more than 50 programs and more than 10 environmental statutes, extensive pollution monitoring in the absence of self-reporting would likely be cost prohibitive. Theory suggests that self-reporting regimes can be designed to be incentive compatible and efficiency enhancing, provided penalties equal (or nearly equal) regulated agents' expected sanctions without self-monitoring (Malik 1993; Kaplow and Shavell 1994). ${ }^{6}$ Social benefits of self-reporting may be particularly pronounced when regulated agents may engage in avoidance or concealment activities (Innes 1999a, 1999b, 2001).

However, natural questions about the accuracy of self-reporting in the real world arise. Record falsification, strategic non-reporting, 'guesstimation', and technical or paperwork mistakes might be common. Should regulators, researchers, and other stakeholders believe self-reported emissions data? Several reasons suggest that the answer for the largest facilities regulated under the major environmental statutes may be 'generally yes.'

First, real world environmental penalty schedules often mimic theoretical penalties necessary for incentive compatible self-reporting. Administrative and civil penalties levied for pollution violations are typically relatively small while civil and criminal penalties levied for intentional falsification and strategic reporting can be very large. Intentional misreporting can, and has historically, also resulted in significant jail time (Shimshack and Ward 2005). Principle-agent issues may also be important, as penalties for intentional reporting may be levied on employees in addition to owners and managers (Cohen 1992).

Second, a few studies have empirically explored self-monitoring for large regulated facilities or other large entities, and have failed to reject a null hypothesis of largely accurate self-reporting (on average). One set of studies explored whether self-reported CWA discharges at large pulp and paper mills changed systematically when regulators conducted inspections (Laplante and Rilstone 1996; Shimshack and Ward 2005, 2008). The intuition was as follows: if self-reports are

\footnotetext{
${ }^{6}$ This will typically involve more frequent regulator punishment across all types of violations. However, Livernois and McKenna (1999) point out that a cost minimizing regulator may combine high sanctions for reporting violations with lower sanctions for pollution violations. They may even fall below those predicted by traditional models.
} 
accurate when inspectors are present and discharges are underreported when inspectors are not present, researchers might detect a positive correlation between on-site inspections and reported pollution (after controlling for inspection targeting). The researchers detected no conditional relationship between inspections and reported pollution, and therefore failed to reject the accuracy of self-reporting for conventional water pollutants in the pulp and paper industry. Other studies have applied the tools of forensic economics to search for statistical patterns consistent with strategic behavior by large self-reporting entities. For example, Chakraborti and Shimshack (2012) failed to reject the accuracy of self-reported conventional water pollution discharges from large chemical, paper, and textile manufacturers. ${ }^{7}$

On a more cautionary note, however, the reliability of self-reported compliance information for facilities other than the largest CWA industrial facilities is poorly understood. Regulators do not conduct and report systematic secret and random checks of self-reported pollution discharges at the regulated monitoring point sources, so the extent of strategic misreporting in many environmental settings is essentially unknown. De Marchi and Hamilton (2006) found statistical results that failed to reject accurate reporting for some EPCRA Toxic Release Inventory (TRI) pollutants, but were consistent with reporting anomalies for lead and nitric acid emissions. Chakraborti and Shimshack (2012) found suggestive evidence that may be consistent with strategic misreporting at municipal wastewater treatment plants. Results from two notable field experiments outside of North America are also instructive. Telle (2013) found that Norweigian manufacturing facilities underreported hazardous environmental releases, and Duflo et al. (2013) found that reforming incentives for third party auditors reduced false self-reporting at industrial plants in the Indian state Gujarat.

The evidence from non-environmental settings also suggests that the potential for the misreporting of self-reported compliance data may be significant, especially for smaller facilities and for individuals where information reporting is limited. Lessons from attempts to estimate tax evasion are instructive. This literature takes essentially four approaches to measuring evasion (Schneider and Enste 2000, 2002; Schneider 2005; Alm 2012). First, direct approaches measure income tax evasion via regulator audits, anonymous surveys, and reporting under governmentsponsored tax amnesties (IRS 2012). Second, indirect macroeconomic-level approaches econometrically explore gaps between reported income and national income accounts, between reported income and national expenditures, between actual labor force participation and official labor statistics, and between money and its velocity (Feige 1994). Third, researchers investigate deviations from generally constant relationships between overall income and physical inputs and outputs like electricity and luminosity (Henderson et al. 2009). Fourth, studies use forensic tools and statistical models based on theories of unobserved variables to investigate income relative to expectations (Frey and Weck-Hannemann 1984; Carslaw 1988).

\footnotetext{
${ }^{7}$ Similarly, Auffhammer and Carson (2007) failed to reject the systematic accuracy of self-reported province-level carbon dioxide emissions by authorities in China.
} 
Nearly all studies estimating tax evasion find that that some proportion of companies and individuals conceal legal market activities to avoid taxes or other regulatory burdens, although variation over space and time is significant. Indeed, the most recent estimates of the U. S. federal 'tax gap' (or the difference between tax revenues actually collected and the amount that should be collected if taxpayers fully complied with the tax laws) indicate a gap of $\$ 450$ billion in 2006, equivalent to a voluntary compliance rate of 83.1 percent. The largest single component of the tax gap was from the individual income tax (\$296 billion), of which most was due to individual underreporting of tax liabilities.

Tax compliance researchers also often measure the size of the overall shadow economy as a proxy for the total extent of evasion at a macroeconomic level. Shadow markets represent all legal economic activities that are concealed from authorities to avoid income or business taxes, social security contributions, labor market requirements, or administrative procedures (Schneider 2005). Researchers find that the size of shadow economies as a portion of GDP are on the order of 40-50 percent in low income countries, 25-40 percent in middle income countries, and 10-20 percent for high income countries (Schneider 2005; Alm and Embaye 2013). Although shadow economies do not represent evasion alone, underreporting in the tax context appears extensive.

Other evidence also suggests the potential for misreporting. For example, in a recent generalsetting regulatory laboratory experiment, Friesen and Gangadharan (2013) found that individuals tasked with reporting accidents to a hypothetical regulator frequently underreported incidents. However, accurate self-reporting increased markedly with mandatory reporting relative to voluntary reporting. The self-reporting schemes that serve as the basis of the dominant monitoring regimes under the major environmental statutes require mandatory reporting, so perhaps this result is somewhat reassuring for environmental self-monitoring. ${ }^{8}$

Nevertheless, the extent to which income evasion, accident reporting, and environmental selfreporting may be comparable is unknown. Results from these other contexts, however, do suggest that regulators and researchers should not simply assume accurate environmental selfreporting. The related literature also suggests that concerns may be especially pronounced for individuals and smaller businesses, when the probability of detected strategic misreporting is extremely low or when some reporting dimensions are voluntary rather than mandatory.

\section{Assessing impacts of environmental monitoring and enforcement}

\subsection{How can inspections and penalties influence environmental performance?}

How do we assess the deterrence effects of environmental monitoring and enforcement? The natural starting point is reflecting on the four ways that monitoring and enforcement actions can

\footnotetext{
${ }^{8}$ Environmental authorities implement voluntary environmental programs, but these programs are beyond the scope of this paper. Pfaff and Sanchirico (2004) and Toffel and Short (2011) empirically assessed the EPA's audit policy, where facilities voluntarily self-report violations in exchange for reduced penalties and favorable regulatory treatment in other dimensions.
} 
enhance compliance and reduce pollution. First, inspections and penalties can have a direct abatement effect. Inspections may reveal easy ways to improve compliance and environmental performance, including improved equipment operation, enhanced equipment maintenance, and better personnel training. Consent orders and judicial settlements may also require facilities to return to compliance, and these requirements may directly reduce pollution. Second, monitoring and enforcement actions can enhance future compliance via 'specific deterrence', where specific deterrence is defined as the effects of inspections or penalties on the future behavior of the monitored or sanctioned firm. Third, monitoring and enforcement actions can enhance future compliance via 'general deterrence', defined as the effects of inspections or penalties due to changes in regulated entities' perceptions of the overall regulatory environment. General deterrence may arise via changes in rules or laws governing inspection probabilities, sanction probabilities, or sanction magnitudes (e.g. Stafford 2002, 2003). General deterrence may also arise from enforcement spillovers where inspections or sanctions directed towards one facility enhance compliance at other facilities via a regulator reputation effect (e.g. Shimshack and Ward 2005).

The fourth way that monitoring and enforcement can enhance future environmental performance is via 'beyond compliance' effects. Although economists and policymakers typically view monitoring and enforcement as tools to achieve compliance alone, Shimshack and Ward (2008) demonstrated that penalties may cause plants to reduce pollution by more than required to meet statutory requirements. Mechanisms for this enforcement-induced overcompliance include pollutant randomness and pollution jointness. When emissions have a stochastic element, plants may reduce pollution to well below permitted levels during periods of perceived enhanced regulatory stringency in order to reduce the probability of accidental violation. When pollutants are jointly produced or jointly abated, plants may reduce one pollutant to well below permitted levels during periods of perceived enhanced regulatory stringency in order to reduce the probability of a violation for a jointly produced or abated pollutant. ${ }^{9}$

\subsection{Empirically and experimentally measuring deterrence effects}

Measuring direct abatement effects from inspections and enforcement actions is straightforward, but identifying specific and general deterrence can be challenging. Abatement effects can be approximated by simply aggregating required pollution reductions under consent orders and other enforcement resolutions. For example, the EPA's Office of Enforcement and Compliance Assurance asserts that civil enforcement cases concluded in fiscal year 2013 required 1.3 billion pounds of air pollution eliminated or treated, 148 million pounds of hazardous waste disposed or treated, and 2 billion gallons of water pollution discharges eliminated. ${ }^{10}$

\footnotetext{
${ }^{9}$ Enforcement uncertainty has been shown theoretically to generate similar effects on tax compliance behavior, depending on taxpayer risk attitudes (Alm 1988; Beck and Jung 1989; Scotchmer and Slemrod 1989).

${ }^{10}$ See the EPA's enforcement annual results numbers for fiscal year 2013, available online at: http://www2.epa.gov/enforcement/enforcement-annual-results-numbers-glance-fiscal-year-fy-2013 .
} 
Specific deterrence is typically measured empirically with regressions of compliance metrics on inspections or enforcement actions at the facility. Dealing with endogeneity, and thus causal attribution, can be challenging. One concern is simple omitted variable bias. For example, many pollutants exhibit strong seasonal patterns and downward trends for reasons other than monitoring and enforcement. If regulatory interventions also follow seasonal or long-term patterns, then statistical correlations between pollution or compliance and interventions may not be causal. Another concern is regulator targeting. For example, regulatory agencies may be more likely to inspect facilities that are more likely to be out of compliance on average. Similarly, even conditional on typical environmental performance, regulatory agencies may be especially likely to inspect facilities during periods of especially likely pollution. Regulatory targeting builds in a potentially misleading positive correlation between pollution or noncompliance and regulator interventions, suggesting that regulator actions are less effective than they really are (or perhaps even counterproductive). A third natural concern with specific deterrence measurement is reversion to the mean. Enforcement actions for pollution violations will always follow periods of noncompliance or high pollution, so compliance may be higher or pollution may be lower after interventions as plants simply return to their average performance steady state. Mean reversion may bias relationships between pollution or noncompliance and regulator interventions in a negative direction, suggesting that regulator actions are more effective than they really are.

Researchers attempt to minimize endogeneity concerns in empirical analyses of specific deterrence in several ways. ${ }^{11}$ Studies often minimize time invariant inspection targeting and omitted variable bias with detailed facility-level characteristics or facility-level fixed effects. Many studies include lagged dependent variables as explanatory variables in order to proxy for capital stock and average propensity to pollute and violate. Nearly all studies control for seasonality and long-term time trends at the national, state, or regional levels. Many studies attempt to minimize reverse causality concerns using lagged explanatory variables. Some papers exploit more plausibly exogenous proxy variables as explanatory regressors, use econometric predictions of facility-specific interventions from two-step procedures, and/or use maximum likelihood instrumental variable approaches. Many, but by no means all, of the more recent papers in the literature endeavor to defend exclusion restrictions or at least identify threats to internal validity and subsequent implications for economics and policy.

Empirically measuring general deterrence presents its own challenges, although somewhat fewer causal attribution concerns arise relative to specific deterrence measurement. One approach to general deterrence measurement is to explore how facilities' environmental performance responds to plausibly exogenous rule changes that influence monitoring probabilities, monitoring intensity, enforcement probabilities, and the magnitude of sanctions. An alternative approach is to regress a facility's pollution or compliance status on interventions levied against other facilities regulated by the same primary authority in the recent past. The underlying assumption of this latter approach, consistent with the law and economic learning model of Sah (1991), is

\footnotetext{
${ }^{11}$ Gray and Shimshack (2011) discuss empirical measurement challenges and potential solutions in detail.
} 
that facilities update their beliefs about the probability or magnitude of their own inspections or sanctions by observing the recent experiences of similar facilities.

Recently, environmental economists and other environmental scholars have begun investigating both specific and general deterrence using laboratory and field experiments. Overall enforcement intensity, as well as the probability of detection, the probability of sanction, and the magnitude of sanction at any given facility, are unlikely to be random in observational data (Telle 2013). Regulated entities' perceptions of inspection and sanction probability and magnitudes can be difficult to observe empirically (Friesen 2012). Data limitations often preclude observational tests of deterrence mechanisms and other hypotheses from theory (Friesen and Gangadharan 2013). For these reasons, experiments measuring and explaining the deterrence effects of environmental monitoring and enforcement are promising and increasingly used.

How do experiments measuring and explaining compliance work? In all cases, subjects respond to changes in enforcement conditions controlled by the experimentalist. Laboratory research designs include public goods games, where free riding may be detected with variable probabilities and sanctioned with variable penalty magnitudes (e.g. Anderson and Stafford 2003). Lab-based methods also examine directly tax compliance decisions, in which subjects receive fixed incomes or other benefits and must decide on whether or not to accurately report the income or benefits when doing so generates costs (e.g. Alm 2012). Some laboratory experiments allocate revenues to subjects and then give them opportunities to comply with costly regulations when facing variable probabilities of detection and variable penalties (e.g. Friesen 2012). Field experiments may send randomized information treatments to regulated entities, randomize audits or penalties, and/or randomly assign enforcement strategies or compliance incentive systems (e.g. Telle 2013; Duflo et al. 2013).

Although experimental approaches have many benefits, they are not a panacea. Potential disadvantages may include sample selection issues, lack of realism, framing concerns, low stakes trade-offs, and the so-called Hawthorne effect (Harrison and List 2004; Levitt and List 2007; Alm 2012). Moreover, while internal validity is often enhanced with well-designed laboratory experiments, external validity may be less compelling.

\section{Do monitoring and enforcement get results? Empirical and experimental evidence from environmental settings}

Do environmental monitoring and enforcement deter violations and reduce pollution emissions? We emphasize here the evidence on specific and general deterrence, with more limited discussion on abatement and beyond compliance effects due to more limited formal evidence. We find that the preponderance of empirical and experimental evidence from environmental settings suggests the answer to this question is a qualified yes, at least for well-studied large pollution sources. Most research results indicate that marginal increases in inspection or fine probabilities are associated with statistically significant enhanced future compliance and/or 
reduced pollution. In some cases, these marginal improvements in compliance or pollution are practically large. The evidence for deterrence from increasing sanction magnitudes is somewhat more mixed.

\subsection{Empirical explorations of specific deterrence in environmental settings}

The evidence for specific rather than general deterrence effects in toxic, hazardous, and household waste contexts is mixed. Nevertheless, some significant specific deterrence is typically detected in most studies. Stafford (2003) found a significant negative association between RCRA facilities' violations and their own lagged inspections. Eckert (2004) found that warnings and inspections increased future compliance at inspected or sanctioned petroleum storage sites, but the effects were small. A doubling of the inspection probability reduced violation probabilities by between 5 and 50 percent. Stafford (2014) failed to detect deterrence effects from federal inspections and civil penalties directed towards oil and gas pipeline operations, although data limitations prevented the author from fully addressing possible reverse causality concerns. Stafford (2014) did find consistent evidence for an association between federal cases initiated and several measures of environmental performance. ${ }^{12}$

For criteria air pollutants regulated under the CAA, the statistical evidence for specific deterrence effects is relatively consistent. Gray and Deily (1996) found that self-reported CAA compliance increased following actual inspections or enforcement actions at the plant, and that compliance also increased when the econometrically predicted probability of a current enforcement action increased. Similarly, Nadeau (1997) determined that changes in noncompliant paper plants' predicted probability of inspections and enforcement actions significantly reduced the length of noncompliance spells; a 10 percent increase in predicted monitoring or enforcement activity reduced a 10 quarter duration of noncompliance to roughly a 6 quarter duration of noncompliance. Gray and Shadbegian (2005) found that a marginal increase in predicted inspections at pulp and paper mills raised the probability of annual compliance by approximately 10 percent, although they also showed that such deterrence effects varied notably across plants. Keohane et al. (2009) found that a one standard deviation higher threat of a new source review lawsuit resulted in a 10 percent reduction in criteria air pollutants at electric utility plants. Conditional on responding to lawsuit threats, however, plants failed to respond further to actually imposed enforcement actions.

Robust empirical evidence for specific deterrence in CWA settings is also available, at least on average across facilities and instruments. Magat and Viscusi (1990) demonstrated that conventional water pollution in the pulp and paper industry fell by approximately 20 percent after inspections, and that the probability of noncompliance was approximately half as high in

\footnotetext{
${ }^{12}$ In a similar vein, Hanna and Oliva (2010) found that air emissions reported under the TRI fell by 15 percent in the period following an inspection but that land and water emissions reported under the TRI were unaffected by inspections. TRI emissions are not directly capped, so their key results apply most directly to pollution rather than compliance outcomes.
} 
periods following an inspection than in periods not following an inspection. In an extension of Magat and Viscusi (1990), Laplante and Rilstone (1996) found that both inspections and the predicted threat of inspections at Canadian pulp and paper mills resulted in a 7-28 percent fall in conventional water pollution discharges. Earnhart (2004a, 2004b) uncovered suggestive evidence that increased predicted threats of inspections and enforcement actions resulted in reduced conventional water pollution discharges at municipal wastewater treatment plants in Kansas; ${ }^{13}$ results on the effects of actually imposed monitoring and enforcement instruments, as well as comparative results on state versus federal interventions, were typically sensitive to specification. Although Shimshack and Ward (2005) focused on assessing general deterrence, they also found that the marginal inspection in the pulp and paper industry enhanced subsequent compliance and reduced pollution at the inspected plant. This effect decayed relatively rapidly over time. Glicksman and Earnhart (2007) studied the chemical industry and found several significant deterrence effects from inspections and fines. Many federal interventions served on average as a greater deterrent than similar state interventions. Shimshack and Ward (2008) found that pulp and paper mills' water pollution discharges fell approximately 5 to 10 percent of permitted levels in the year following a fine at the plant. Earnhart and Segerson (2012) found no average deterrence effects for federal inspections and sanctions at U.S. chemical facilities, but did find significant yet small specific deterrence effects from state inspections. They also showed that deterrence effects were strongly influenced by financial status, and that detected average deterrence effects can be misleading in settings with substantial heterogeneity.

\subsection{Empirical explorations of general deterrence in environmental settings}

Several particularly early studies found strong evidence for general deterrence in an oil pollution setting. Epple and Visscher (1984) found that the size of oil spills by tankers and barges fell significantly with respect to overall enforcement effort by the U.S Coast Guard. The deterrence effects of cleanup requirements and penalties, however, were considerable larger for ships than for barges. Although Cohen (1987) was primarily concerned with understanding the optimality of regulator enforcement strategies, he also demonstrated that Coast Guard patrols and oil transport observation activity significantly reduced the size of oil spills. In contrast, inspections devoted towards specific vessels had no clear impact on spill size. Grau and Groves (1997) determined that Coast Guard monitoring had practically large and statistically significant negative effects on oil spill size and especially spill frequency (which was not studied in earlier work). Marginal increases in expected fine magnitudes had no consistent impact on the frequency and size of oil spills.

General deterrence effects have also been regularly detected in toxic, hazardous, and household waste settings. Alberini and Austin $(1999,2002)$ found that strict liability regimes reduced both the probability and size of toxic pollution releases, although deterrence effects were quite

\footnotetext{
${ }^{13}$ Magat and Viscusi (1990), Laplante and Rilstone (1996), and Earnhart (2004a), along with a study by Helland (1998) exploring the causes and consequences of dynamic inspection targeting, also showed that inspections lead to increased probability of timely self-reporting.
} 
heterogeneous across firms. Stafford (2002) discovered that hazardous waste generators regulated under the RCRA violated less frequently following a significant increase in maximum allowable penalties, although the decrease was small relative to the size of the change in legal limits. In a related study, Stafford (2003) determined that the most serious RCRA pollution violations declined in states that adopted strict liability regimes and were lower in states with higher proportions of employees located in regional offices. On a cautionary note, the paper also provided suggestive evidence of strategic reporting; the adoption of strict liability regimes appears to have increased recordkeeping and reporting violations. Eckert (2004) found evidence that a change in higher maximum fines reduced violations from Canadian petroleum storage tanks. Finally, Almer and Goeschl $(2010,2013)$ showed that an increased probability of criminal punishment reduced illegal waste dumping and other environmental crimes by German citizens. The study also showed that deterrence effects from increasing penalty magnitudes were smaller than deterrence effects from an increased probability of standing trial in a public court.

Instead of focusing on the effects of rule changes or general enforcement propensities, several recent air and water pollution compliance studies have directly analyzed the spillover effects of enforcement levied towards one plant on the behavior of other facilities. Shimshack and Ward (2005) found that the statewide probability of conventional water pollution violation fell roughly 60 percent in the year following a rarely imposed fine on any facility in the same state and sector, and that the statewide probability of violation fell roughly 27 percent in the second year following a fine in the same state and sector. Nearly all of these effects were attributable to enforcement spillovers since non-fined plants responded nearly as strongly to sanctions as the fined plant itself. Although fines generated large deterrence effects, non-pecuniary informal enforcement actions had no impact on compliance. Gray and Shadbegian (2007) explored spatial aspects of criteria air pollution compliance at U.S. manufacturing facilities in detail. Deterrence results established that inspections significantly enhanced subsequent compliance at both the inspected facility and at other facilities in the same state. Notably, detected general deterrence effects were restricted by state boundaries, highlighting the importance of regulatory jurisdictions. ${ }^{14}$

Shimshack and Ward (2008) demonstrated that the enforcement spillovers underlying general deterrence can influence not just compliance behavior, but beyond compliance behavior and overcompliance as well. The research showed that typically compliant pulp and paper mills responded to fines on other facilities in the same state and sector by reducing discharges even if they were unlikely to violate anyway. They also showed that, when fines signaled the regulator's reputation for toughness, mills that may have violated reduced discharges by significantly more than was required to meet statutory requirements alone. As mentioned above, this behavior can

\footnotetext{
${ }^{14}$ General deterrence effects in environmental settings are also strongly supported by the qualitative survey results of Carlough (2004) and Thornton et al. (2005). Note also that Earnhart (2004a, 2004b) empirically found that environmental performance responded to overall enforcement intensity and/or regulator actions directed towards other facilities, although he did not discuss or interpret these general deterrence results.
} 
be rationalized by models with stochastic discharges and jointly produced pollutants. Stochastic discharges may induce plants to respond to periods of perceived regulatory stringency by reducing discharges well below permitted levels in order to avoid accidental discharges. Jointly produced or abated pollutants may induce facilities to respond to periods of perceived regulatory stringency by reducing discharges well below permitted levels for one pollutant in order to avoid violations by a joint co-pollutant.

Emerging empirical evidence also suggests important general deterrence effects of private, rather than public, enforcement. Langpap and Shimshack (2010) found evidence that private citizen suits in a state reduced wastewater treatment plants' subsequent probability of a violation by approximately 15 percent. The study also demonstrated that private citizen suits significantly crowded out public enforcement. As a consequence, although citizen suits did generate important deterrence effects, their impacts on facilities' environmental performance were somewhat offset by corresponding reductions in state and federal EPA enforcement intensity.

\section{Empirical explorations of deterrence in other settings}

In this section, we consider enforcement and compliance lessons from occupational safety and tax compliance settings. We focus on health and safety because the Occupational Safety and Health Administration (OSHA) and EPA both have broad regulatory mandates and because many OSHA and EPA monitoring and enforcement programs have similar institutions (at least in states with approved 'state plans'). We focus on tax compliance because of extensive data availability and because of a rich and diverse existing literature.

Important differences between pollution and occupational safety and/or tax settings exist. Most notably, strong non-regulatory incentives for occupational safety are likely absent from the environmental setting. The tax literature emphasizes individuals' compliance while the environmental literature emphasizes organizational compliance. We draw out contextual differences in more detail more below. Readers are nevertheless cautioned not to over-interpret safety and tax results for the environmental context.

\subsection{Empirical and experimental evidence from occupational safety settings}

Do monitoring and enforcement actions in other settings deter violations and enhance performance? Despite relatively robust evidence that inspections and fines enhance compliance and improve performance in many environmental settings, empirical evidence for significant deterrence in occupation safety settings is more mixed. Recent literature surveys by Ruser and Butler (2010) and Leeth (2012) conclude that historical monitoring and enforcement by OSHA generated little meaningful effects on safety at industrial facilities. ${ }^{15}$ Some individual studies come to different conclusions, but even these papers note substantial heterogeneity in deterrence effects across space and time.

\footnotetext{
${ }^{15}$ This section draws from Ruser and Butler (2010), Gray and Shimshack (2011), and especially Leeth (2012).
} 
In studies using occupational safety data from the 1970s, a time when penalties for noncompliance were especially low, the empirical evidence indicates negligible or moderate effects of OSHA interventions on safety and health outcomes. Using data from the early 1970s, Viscusi (1979) detected no statistical relationship between inspections or penalties at industrial facilities and health and safety investments or worker injuries. Using data from 1974-1978, Bartel and Thomas (1985) found that a long-run doubling of inspections would enhance workplace safety by roughly 26 percent. However, Bartel and Thomas (1985) also demonstrated that the effects of such a change on safety outcomes would be small because links between noncompliance and lost workdays were weak. Using data from 1973-1983, Viscusi (1986) detected a statistically significant but economically small (1 to 4 percent) reduction in lost workdays following OSHA inspections. Results for other outcomes, however, were insignificant or inconclusive.

Research using industrial data from the 1980s also finds mixed deterrence effects, and results within and across studies remain quite heterogeneous and not terribly robust. Using a large dataset of industrial establishments, Ruser and Smith (1991) found scarce evidence that OSHA inspections generated any significant specific or general deterrence effects. In contrast, Scholz and Gray (1990) found that a 10 percent increase in inspections or penalties at manufacturing facilities reduced subsequent workplace injuries by approximately 1 percent. Gray and Scholz (1993) re-examined a similar dataset, and also uncovered practically meaningful specific deterrence effects. A key insight of this and related studies was that deterrence was largely driven by inspections accompanied by penalties; inspections that were not accompanied by penalties had little or no deterrence effect (Gray and Mendeloff 2005; Gray and Shimshack 2011).

More recent research finds more consistent deterrence effects from OSHA interventions, but specific magnitudes remain context dependent. Gray and Mendeloff (2005) found that OSHA inspections associated with penalties reduced workplace injuries on average across manufacturing facilities, but results declined over time from a roughly 19 percent deterrence effect in the early 1980 s to a statistically insignificant 1 percent deterrence effect in the mid1990s; deterrence was also greater at smaller facilities. Mendeloff and Gray (2005) found that OSHA penalty inspections at small to medium-sized manufacturers in the 1990s reduced both injuries related to compliance and spilled over to reduce injuries largely unrelated to OSHA requirements. Haviland et al. $(2010,2012)$ found similar results with more recent data from Pennsylvania. ${ }^{16}$ Levine et al. (2012) conducted a randomized controlled field experiment in California, and found large deterrence effects of OSHA inspections. Inspected facilities experienced an approximately 9 percent decline in injuries and a 26 percent decline in injury costs relative to a matched control group of facilities eligible for inspections but not inspected.

\footnotetext{
${ }^{16}$ Leethe (2012) cautions against over-interpreting these results, as very small and large facilities (where deterrence effects may be especially weak) were omitted from the analysis.
} 
We summarize the recent evidence as favorable towards at least some measurable specific and general deterrence effects of OSHA interventions. However, it does seem clear that the effects are likely smaller and less robust than evidence for deterrence from state and EPA environmental regulatory actions. Moreover, as Ruser and Butler (2010) and Leeth (2012) noted, OSHA inspections and penalties certainly seem unlikely to be the dominant driver of the very large and persistent fall in workplace injuries and fatalities over the past four decades.

In contrast to occupational safety settings, qualitative survey evidence typically suggests that enforceable regulations are likely the leading cause of environmental behavior and environmental improvements at large point sources since the 1970s (Kagan et al. 2003; Khanna and Anton 2002; Doonan et al. 2005; Delmas and Toffel 2008). In many respects, this divergence may seem surprising given that the literature on occupational safety and environmental performance often studies similar samples of industrial facilities governed by similar institutions, as noted earlier. However, the occupational safety setting is characterized by very strong labor market forces via compensating wage differentials, more direct avenues for legal liability, and worker's compensation programs. Workers themselves have strong incentives for occupational safety. Similarly strong and increasing incentives to minimize workplace injuries in the absence of OSHA regulation may not necessarily exist for environmental performance. $^{17}$

\subsection{Empirical and experimental evidence from tax compliance settings}

In environmental settings, compliance requires accurate self-monitoring (or agency monitoring) and a behavioral choice that results in realized pollution levels falling below allowable pollution levels. In tax evasion settings, accurate reporting itself is largely the compliance outcome of interest. As a consequence, empirically measuring the effects of audits and enforcement on tax evasion also involves simultaneously measuring the extent of evasion, as discussed in Section 3.2 above. Experimental approaches where compliance is directly observed are also increasingly common.

In early work, Dubin et al. (1987, 1990) used a panel of state-level data from the IRS's Annual Report to estimate the determinants of income tax reporting for the years 1977 to 1985 . After controlling for the endogeneity of the audit rate, both studies found that higher audit rates typically had a positive impact on income tax reporting; however, results varied by audit class and were not always statistically significant. Dubin et al. $(1987,1990)$ also found general deterrence spillover effects from tax audits. Taxpayers who were not themselves audited paid more in taxes when audit rates increased. Estimated spillover effects varied between 6 and 8, which implies that $\$ 1$ of additional revenue generated from an audit generates an additional $\$ 6$ to

\footnotetext{
${ }^{17}$ Both occupational safety and environmental performance are influenced by corporate social responsibility considerations that provide strong economic incentives. These incentives alone, however, are quite unlikely to explain long-run improvements in environmental quality, workplace safety, and other pro-social behaviors. See Kitzmuller and Shimshack (2012) for a detailed survey of the evidence.
} 
$\$ 8$ of revenues from individuals who are not audited.

Plumley (1996) extended the analysis of Dubin et al. $(1987,1990)$ using state-level data from 1982 to 1991 . He found that criminal enforcement activities were significant and positively related to compliance. Dubin (2007) used similar data and dynamic panel techniques to examine the effects of criminal investigation enforcement activities on taxpayers' compliance behavior for the years 1988 and 2001. Results indicated that criminal investigation activities often had a measurable and significant effect on voluntary tax compliance. Incarceration and probation had the most significant effect on reported taxes, while sentenced cases and media attention did not have a significant influence.

Other studies have used (often aggregated) individual taxpayer data to empirically estimate relationships between monitoring and enforcement and compliance. Witte and Woodbury (1985) and Dubin and Wilde (1988) used U.S. Taxpayer Compliance Measurement project data from 1969, aggregated to the 3-digit zip code level and broken down by audit class, to estimate the impact of audit rates on a predicted measure of noncompliance. Witte and Woodbury (1985) found significant and widespread deterrence effects of audits on noncompliance. However, Dubin and Wilde (1988) more carefully controlled for the potential endogeneity of audit rates, and found a significant impact for only one of the seven audit classes on noncompliance. Bergman and Nevarez (2006) used individual tax return data for Argentina and Chile, and found a similarly nuanced result. They found that audits did not deter cheating by individuals already found to be cheaters but did deter cheating by individuals previously found to be compliant.

More recently, Alm and Yunus (2009) used U.S. state-level panel data for the years 1979 to 1997 to estimate the factors that affect per return evasion of individual income taxes. Although primarily concerned with issues related to intertemporal and spatial spillovers, they found large specific and general deterrence effects of audits on noncompliance. After accounting for audit endogeneity, they estimated that raising the audit rate by one percentage point decreased the level of evasion by 0.5 percent. This response translated to an immediate, short-run reduction of tax evasion of more than $\$ 1500$ per individual and a long-run reduction in evasion of more than $\$ 2000$ per individual.

A few recent studies explore on the impact of public disclosure on tax compliance. Many states publicize the names of tax evaders, believing that such public 'shaming' acts as a deterrent. However, the deterrent effects of public disclosure are somewhat mixed. Hasegawa et al. (2012) examined the impact of public disclosure in Japan, and found little evidence that disclosure encouraged compliance. In fact, the Japanese system included a threshold for public disclosure, and large numbers of individual and corporate taxpayers whose tax liability would otherwise have been close to the threshold actually underreported income in order to avoid disclosure. This response was clearly in the opposite direction than what was intended. In contrast, Slemrod, Thoresen, and Bø (2013) examined a 2001 change in Norway's disclosure policies, in which anyone with internet access could obtain information on taxes paid. They found that the 
provision of public disclosure via the internet increased reporting by about 3 percent among business owners living in areas where the switch to internet disclosure represented a large change in access.

In response to the inherent difficulties with observational data, researchers are increasingly turning to other applied approaches that use some form of a 'controlled experiment.' One approach is to construct controlled field experiments, which typically entails a treatment sample of individuals receiving a letter or notification telling them some policy-relevant information (e.g., 'your tax return will be closely examined'). A control sample receives a neutral message. These studies typically find that the 'closely examined' message (e.g., a higher audit rate) increases reporting, although impacts are often small, sometimes insignificant, and occasionally in the opposite direction (Slemrod et al. 2001; Iyer et al. 2010; Kleven et al. 2011; Pomeranz 2013). Note that these controlled field studies typically measure reporting decisions, rather than measures of evasion itself.

Other researchers have conducted laboratory experiments. Laboratory methods allow many factors suggested by theory to be introduced in experimental settings and generate precise data on individual compliance outcomes. Notably, lab experiments also allow single policy dimensions to be changed one-at-a-time, which facilitates the separate identification of the effects of a single policy instrument. ${ }^{18}$ Most compliance experiments involve subjects in a controlled laboratory who are told that they should feel free to make as much income as possible. At the beginning of each round of the experiment, each subject is given (or earns) income and must decide how much income to report. Taxes are paid at some rate on all reported, but not on underreported, income. However, underreporting is discovered with some probability and an audited subject must then pay a fine on unpaid taxes. The process is repeated for a given number of rounds. At the completion of the experiment, each subject is paid an amount that depends on his or her performance during the experiment. Into this microeconomic system, researchers introduce policy changes like increased audit probabilities or new audit rules.

Virtually all aspects of compliance have been examined in some way in experimental work, starting with Friedland et al. (1978) and extending to subsequent work by Becker et al. (1987), Beck et al. (1990), Webley et al. (1991), Kirchler (2007), and Torgler (2007), among many others. See Alm (2012) for a comprehensive survey. These studies typically find that a higher audit rate leads to more compliance, with an estimated reported income-audit rate elasticity that varies within the narrow range of 0.1 to 0.2 . The impact appears to be somewhat nonlinear, however, so that the deterrent effect of a higher audit rate eventually diminishes. Most studies have found that compliance increases but only slightly with increases in the fine rate on unpaid

\footnotetext{
${ }^{18}$ There are reasons for caution in the use and interpretation of experimental economics, including the reliance upon student subjects, the presence of 'pro-social behavior', and its overall 'artificiality.' Recent work by Alm et al. (2014a), however, indicates that external validity of laboratory experiments is high. In particular, results with students are largely the same as results with non-students.
} 
taxes. ${ }^{19}$ Public disclosure of non-compliance acts as an additional penalty mechanism. Another common finding is that the spillover effects from audits are generally about 4 to 12 times larger than their direct specific deterrence effects.

A particularly notable finding from tax compliance lab experiments is that deterrent effects are heavily dependent upon the information that taxpayers have about audit and penalty rates; that is, perceptions about the frequency and severity of audits and sanctions matter far more for agents' compliance behavior than their actual frequency and severity. Many subjects also strongly and systematically overweight the probability of an audit, and some subjects may similarly overestimate the penalties for noncompliance.

Taken as a whole, empirical and experimental results from the tax compliance literature are generally suggestive, but not universally supportive, of deterrence effects from enforcement and audits (Alm 2012). Deterrence effects tend to be nonlinearly increasing at a decreasing rate. General deterrence and spillover effects, when measured, are considerably larger than specific deterrence effects alone. Deterrence effects of more frequent audits are greater than the deterrence effects of more severe penalties. Perceived monitoring and enforcement frequency and intensity influence behavior more than actual monitoring and enforcement intensity.

Our interpretation is that these basic deterrence results for tax compliance are roughly consistent with results from the environmental monitoring and enforcement context. In many respects, the similarities may seem surprising as the literature on tax compliance focuses more on individual decision-making while the literature on environmental compliance focuses more on facility or firm decision-making. Moreover, the ultimate behavior of interest in tax compliance settings is reporting while the ultimate behavior of interest in environmental compliance is pollution and its impacts on health and welfare. Pollution is also typically directly observable to regulators and third parties, at least to some extent. Nevertheless, both settings may lack the strong labor market and legal liability forces common in occupational safety contexts.

\section{Explaining compliance}

How and why do inspections and sanctions achieve compliance and reduce pollution? The previous two sections have reviewed the empirical and experimental evidence on the abatement, specific deterrence, general deterrence, and beyond compliance effects of monitoring and enforcement in environmental and related contexts. This section reviews what we know about the underlying mechanisms and motivations. We focus on two paradigms: the simple 'rational actor paradigm' and the 'socio-behavioral paradigm'.

\subsection{The simple rational actor paradigm}

\footnotetext{
${ }^{19}$ In contrast to the tax compliance finding that increases in audit probabilities systematically enhance deterrence more than equivalent increases in penalty magnitudes, laboratory evidence by Anderson and Stafford (2003) and Friesen (2012) find that changes in the penalty magnitude matter more than changes in the probability of detection in a generic regulatory and criminal setting.
} 
Since Bentham (1789), law and economics scholars have considered rational agents facing tradeoffs from breaking a law or violating a regulatory obligation. In this model, the potential violator maximizes utility or profits by weighing the expected benefits of noncompliance against the expected penalties from noncompliance. Expected penalties are a function of the perceived probability of detection and the perceived magnitude of the penalty conditional on being caught violating. This framework is transparent and well understood, so we do not belabor the formalism here. Becker (1968) provided the seminal law and economic treatment, Allingham and Sandmo (1972) applied the model to tax evasion, Viscusi (1979) and Smith (1979) developed early applications for OSHA and regulatory compliance, and Russell et al. (1986) applied the model in a pollution context. Ruser and Butler (2010), Alm (2012), and Shimshack (2014) discuss notable extensions for OSHA, tax, and environmental compliance settings, respectively. This simple rational actor paradigm is sometimes referred to as the economics of crime model, the calculated motivation model, or the expected utility model.

Three issues within the simple rational actor paradigm bear emphasis for pollution contexts. First, compliance realizations may have a stochastic element, so the decision-maker's true choice variable may be abatement effort or target emissions rather than deterministic emissions or compliance. Second, the majority of environmental violations that are self-reported or detected by violators during inspections are not formally sanctioned by authorities. Therefore, expected penalties of noncompliance are more completely characterized by the probability of detection, the probability of sanction conditional on detection, and the magnitude of the penalty conditional on levied sanction. Third, the costs to firms of incremental environmental performance and compliance vary enormously from one setting to another; that is, significant changes in abatement may require either large capital investments and costly changes in production, or inexpensive employee training, incremental equipment maintenance expenses, and small changes to abatement conditions. ${ }^{20}$

The rational actor model with or without the simple extensions described above has been the workhorse of the economics literature on environmental compliance. This fact is surely due to its elegance, simplicity, and sensible predictions. The model yields the natural hypotheses that increased agent perceptions of the probability of detection, the probability of sanction, and the magnitude of sanction will be associated with improved compliance and performance.

Exogenous rule changes that increase inspection or enforcement frequency will enhance general deterrence. If inspections or enforcement actions at other facilities cause agents to upwardly adjust their beliefs about their own expected penalties, then general deterrence spillover effects arise. If inspections or enforcement actions at an agent's own facilities cause the agent to

\footnotetext{
${ }^{20}$ For example, common biological wastewater treatment involves a delicate balance of microorganism, acidity, temperature, light, nutrient, and substrate conditions (Thompson et al. 2001). Increased attention to these matters can significantly and rapidly enhance environmental performance. Note also that some scholars have even asserted that environmental compliance costs can be negative in certain dynamic settings (Porter and van der Linde 1995). That is, over the long run, regulation-induced environmental compliance saves the regulated entity money. However, widespread empirical evidence for this hypothesis is limited (Jaffe et al. 1995).
} 
upwardly adjust their own beliefs about subsequent inspection or enforcement probabilities or penalties, then specific deterrence arises. If inspections or enforcement actions highlight easily correctable issues or achieve immediate abatement, abatement effects occur.

\subsection{Extending the simple rational actor paradigm}

A common concern with the economics of crime model as an explanation for real-world environmental behavior is that many stakeholders assert that observed compliance is generally high while expected penalties appear low. From our perspective, we argue that characterizing overall environmental compliance as 'generally high' is debatable. However, it is indeed hard not to conclude that expected penalties seem low for virtually all standard environmental compliance decisions. The size of the regulated universe is large, agency monitoring is infrequent, median levied administrative penalties are typically on the order of a few hundred to a few thousand dollars, and civil and criminal enforcement actions are extraordinarily rare. This apparent compliance paradox could be justified in the rational actor model by very low costs of compliance or high non-market penalties for noncompliance. Although circumstances where compliance costs would be expected to be low sometimes arise (Thompson et al. 2001; Shimshack and Ward 2008), overall pollution abatement expenditures across manufacturing facilities alone reach many billions of dollars per year (U.S. Census Bureau 2008). Additionally, a nearly universal finding in the experimental tax compliance literature, where the relevant theory is directly testable, is that researchers observe far more compliance than is predicted by expected utility theory alone, even if they also find consistent evidence that deterrence does in fact deter (Alm 2012). Thus, it seems quite unlikely that simple static expected utility calculations entirely explain many real-world environmental compliance behaviors.

So what might explain generally high compliance in the face of generally low expected penalties? One strand of the literature extends the rational actor paradigm to dynamic or multidimensional compliance dimensions. Building on the early work of Landsberger and Meilijson (1982), Harrington (1988), Harford (1991, 1993), Harford and Harrington (1991), and Friesen (2003) have modeled a dynamic game between the regulator and polluters. Agents that generally comply receive infrequent monitoring and lenient penalties for noncompliance, while agents considered 'bad apples' based on their compliance history receive frequent monitoring and severe penalties for noncompliance. This targeting regime generates enforcement leverage where agents are more likely to comply than expected when average static expected penalties seem low, because violating in the present increases the probability of being moved to the 'bad apple' group and being punished severely in the future. ${ }^{21}$ Heyes and Rickman (1999) have applied

\footnotetext{
${ }^{21}$ See also theoretical work on tax compliance in which an individual's audit probability is not fixed and random but is instead variable and endogenous, dependent in part on the behavior of the taxpayer and on the tax authority. The endogenous audit selection rules that emerge from these various models can be shown deter more evasion than a simple random audit rule based only on current period declarations. See Reinganum and Wilde $(1985,1986)$, Greenberg (1984), Graetz et al. (1986), Sanchez and Sobel (1993), and Cronshaw and Alm (1995) for illustrative examples.
} 
similar logic in a cross-sectional game between the regulator and polluters. Agents that generally comply on many compliance dimensions may receive some leniency on other compliance dimensions, while agents with noncompliance on many dimensions are punished more severely. This game generates enforcement leverage where agents are more likely to comply than expected when average expected penalties seem low across compliance dimensions, because they are seeking leniency in some singular dimension. Shimshack and Ward (2008) similarly showed that compliance for any given contaminant may be influenced by expected penalties for a jointly produced or abated contaminant. Here, a facility may comply with a given pollution target, or even go well beyond compliance with a given pollution target, when expected penalties are low for that pollutant in order to avoid triggering a penalty on a joint pollutant.

\subsection{The socio-behavioral paradigm}

Other observers have explained unexpectedly high compliance coupled with low expected penalties by referencing socio-behavioral motivations for compliance. Scholars increasingly argue that environmental compliance may be prompted by social pressures, normative duties, fairness, social norms, bounded rationality, and other motivations that do not fit neatly in the simplest rational actor models (Ayres and Braithwaite 1992; Burby and Patterson 1993; Kagan et al. 2011). Researchers cite surveys on environmental compliance decisions, as well as the common perception that regulated entities frequently undertake actions not explicitly required by legal requirements (Delmas and Toffel 2008). Evidence from related settings, especially from laboratory experiments, also strongly supports compliance motivations that go well beyond the simple rational actor model alone.

The rational actor paradigm in its simplest form is based on several main assumptions, all of which are common to the standard neoclassical paradigm: individuals are rational, they have unlimited willpower, and they are purely self-interested. However, there is increasing evidence that these are unrealistic depictions of many individuals and organizations. Contrary to the simplest approach, decision makers are affected by the ways in which choices are 'framed'; they face limits on their ability to compute; they systematically misperceive, or do not perceive at all, the true costs of actions; they face limits on their 'self-control'; they are motivated not simply by self-interest, but also by notions of fairness, altruism, reciprocity, empathy, sympathy, trust, guilt, shame, morality, alienation, patriotism, social customs, social norms, and many other objectives; and they are influenced by the process (e.g. voting rules) and social context (e.g. diversity) of decision-making. These 'deviations' from the simplest rational actor model can be classified into three broad areas: non-standard preferences (like other-regarding preferences), imperfect optimization (stemming from, say, limited computation abilities), and bounded selfcontrol (as demonstrated by hyperbolic discounting). See, for example, Congdon, Kling, and 
Mullainathan (2011) for a detailed discussion and Arielly (2008) for a more 'popular' discussion. $^{22}$

Environmental compliance motivations deemed 'social pressures' may include investor preferences, managerial preferences, employee pressures, consumer pressures, and activist pressures (Kagan et al. 2003). Kitzmuller and Shimshack (2012) survey the empirical literature on non-regulatory incentives for prosocial corporate behavior. Empirical evidence supporting a direct investor preference mechanism is weak. Investors matter, and a large literature demonstrates that markets respond to firms' environmental performance (Konar and Cohen 1996; Klassen and McLaughlin 1996; Khanna et al. 1998; Beatty and Shimshack 2010). However more recent evidence suggests that investor responses to environmental performance may be driven more by investor beliefs about firm profitability through other channels like consumer and activist pressures than through investors' own direct preferences for good environmental performance (see, for example, Lyon and Shimshack 2012). Evidence for employee pressures is mixed. Although surveys often suggest that employees are willing to make significant sacrifices to work for socially responsible firms, the growing empirical literature on the "donated labor" hypothesis is on balance not supportive of these claims (Ruhm and Borkowski 2003). However, qualitative and quantitative evidence does support the hypothesis that supply chains, final consumers, and activists influence environmental performance (Kitzmuller and Shimshack 2012). These social pressure channels may generate strong nonregulatory benefits for many environmental compliance decisions, although such benefits most often arise only for a subset of socially differentiated agents. Gunningham et al. (2004) conducted site visits and interviews at 14 pulp and paper mills, and found that many managers reported that social license pressures influenced compliance choices. Similarly, survey responses by farmers, homebuilders, and boat builders indicated that reputational capital with local stakeholders was a key driver of environmental behavior (May 2005).

Environmental compliance motivations deemed 'normative considerations' may include perceptions about the appropriateness of legal requirements, a sense of civic duty, moral or ideological factors, and social norms (Burby and Patterson 1983; Tyler 1990; Simpson et al. 2013). A survey of over 1,500 Danish farmers found that compliance with agro-environmental rules was influenced by agent beliefs about rule fairness and moral obligations to comply (Winter and May 2001). Moreover, regulated farmers expressed significant concerns about others' environmental behavior and social norms. Gunningham et al. (2005) conducted interviews with managers at 35 chemical and electroplating facilities, and they found that

\footnotetext{
${ }^{22}$ Note that the rational actor model can be modified to incorporate some of these considerations, such as social pressures and social norms; that is, an agent's expected utility may depend upon one's reputation with customers, activist actions, regulatory costs, and other similar considerations. Cohen (1999) discusses these issues in some detail. The importance of social pressures and social norms by no means invalidates the rational actor paradigm, even if these considerations were not directly included in the earliest law and economic models. Even so, we believe that extensions of the neoclassical paradigm to incorporate fully all of these considerations takes the rational actor paradigm beyond its basic foundations.
} 
approximately fifty percent of respondents cited normative motivations for some compliance choices. These managers believed that compliance was the 'right thing to do', that they should especially endeavor to comply with fair rules applied fairly, and that frequent or egregious violators should be punished. Thornton et al. (2005) interpreted survey results from 233 firms in 8 industries as evidence that general deterrence was often motivated by 'reassurance' that compliance was not pursued in vain. Simpson et al. (2013) surveyed employees at two USowned manufacturing companies, and found that environmental offenses were less likely when legal sanctions or informal sanctions like losing respect among family and peers were especially likely or large.

A final factor influencing environmental compliance decisions that falls outside the traditional rational actor paradigm is agents' ability to fully understand complex and flexible legal requirements (Spence 2001). Confusion may arise due to bounded rationality or other threats to mental accounting (Kahneman 2003). Burby and Patterson (1993) empirically studied compliance with North Carolina's erosion control programs, and found that the clarity and simplicity of control procedures was a crucial determinant of compliance. Winter and May (2001)'s study of Danish farmers noted that rule awareness importantly influenced ultimate compliance. In an empirical study of thousands of hazardous waste generators and management facilities, Stafford (2006) found that smaller facilities and facilities with more complex rules had more frequent violations, ceteris paribus. While such results may be consistent with multiple hypotheses, they are most suggestive of a role for complexity in environmental performance.

The evidence from outside environmental settings, and especially from the tax compliance literature, also indicates that compliance motivations transcend the rational actor model alone. What governments do with tax revenue influences the extent of evasion (Cowell and Gordon 1988). Guilt, shame, fairness effects, and social conformity have consistently been shown to affect tax compliance (Myles et al. 1996; Fortin et al. 2007). Framing, including the credibility of sources of information about monitoring and enforcement probabilities, significantly alters reporting choices (Alm et al. 2009). Social norms, fairness, trust, customs, morale, and patriotism regularly affect evasion levels (Elster 1989; Andreoni et al. 1998; Alm 2012). In a recent experiment, Alm et al. (2014b) found that telling an individual about what their "neighbors" were doing increased tax compliance when the neighbors were compliant but decreased tax compliance when neighbors were non-compliant. ${ }^{23}$ Alm and Yunus (2009) found strong persistence and spatiality in U.S. tax reporting data from 1979 to 1997, where 'persistence' indicated agent learning over time and 'spatiality' indicated the significant exchange of information between taxpayers.

Although studies too often explain compliance in terms of the rational actor approach or in terms of one or more socio-behavioral explanations, these varied compliance motivations are not

\footnotetext{
${ }^{23}$ Although not in a direct compliance context, similar findings in the energy efficiency context suggest that notifications comparing households' energy use to their neighbors' energy use reduces consumption. See, for example, Allcott (2012).
} 
mutually exclusive. In many - if not most - circumstances, rational calculations of expected costs and benefits, social pressures, normative factors, social interactions, and information processing factors simultaneously influence environmental performance and environmental compliance. Moreover, these many motivations likely interact to strengthen or weaken individual compliance motivations. For example, Kagan et al. (2011) interpreted survey results as supportive of interaction effects between motivations loosely termed fear and duty. In this framework, most agents will comply as long as they are reassured that that cheaters will be significantly punished; however, if they believe that cheaters will escape sanctions, then the social norm of compliance will disappear and cheating will increase.

\section{Lessons, Recommendations, and Conclusions}

What can we learn about designing and implementing more effective and more cost effective public policies for the environment? A first lesson is that environmental monitoring and enforcement actions get results in the real world, at least for well-studied large industrial and municipal point sources. Inspections and enforcement actions achieve direct abatement effects, meaning that they reduce pollution immediately via operations guidance or regulatory settlement agreements. Inspections and enforcement actions also generate specific deterrence, meaning that they enhance future compliance at the monitored or sanction facility. Inspections and enforcement actions also create general deterrence, meaning that enhance future compliance at all facilities within a regulatory jurisdiction. A key mechanism is that enforcement actions directed towards one facility spillover to enhance compliance at other facilities. Inspections and enforcement actions can even spur beyond compliance behavior, where regulator interventions lead to environmental improvements that go well beyond those directly required by legal obligations.

As a corollary, a second lesson is that the basic rational actor paradigm appears to explain a very significant amount of real world polluting behavior. On average, marginal changes in the probability of inspection, the probability of sanction, and/or the magnitude of penalties enhance compliance and improve environmental performance. In contrast, the impacts of informal regulatory enforcement actions without 'teeth' (like warning letters, phone calls, and orders to return to compliance that are not accompanied by pecuniary penalties) appear small or insignificant. Despite theoretical equivalence, incremental changes in fines appear to have a more predictably significant impact on large point sources' environmental compliance behavior than incremental changes in inspections. Although more severe enforcement actions enhance compliance, they may do so at a diminishing rate. Empirical evidence therefore suggests that increases in formal financial penalties may be the most effective way to increase compliance and performance, and more frequent penalties may generate more total deterrence that more severe penalties.

A third lesson is that the literature generates identifiable insights about basic monitoring and enforcement tools. For one thing, it is certainly possible to design and implement a self- 
monitoring system that creates conditions for cost effective and generally accurate reporting. Key features of such a system include at least some continued regulator inspections, large penalties for deliberate falsification and non-reporting, and sanctions that span multiple levels of management. Effective self-monitoring systems may also require more frequent but smaller penalties for self-reported violations. Nevertheless, several strands of the broad literature indicate that self-reporting is not a panacea. Particular care should be paid to self-reporting regimes with many small entities or individuals, as reporting problems may be especially likely in these settings. Also, monitoring and enforcement regimes should be as holistic as possible; that is, the design of regulatory systems should recognize that pollutants can be substitutes or complements in production and abatement, that interventions directed solely towards a single pollutant (or group of pollutants) will be inefficient because monitoring and enforcement actions in one dimension may increase or decrease pollution in other dimensions (Greenstone 2003; Shimshack and Ward 2008), and that dynamic interactions between agents and the regulator should be built into regulatory design and evaluation. Finally, since the spillover effects underlying general deterrence require that other regulated entities know about enforcement activity in their industry or area, interventions should be widely publicized where possible. Spillover effects also require that regulators do not over-target monitoring and enforcement activity. Widespread general deterrence requires some randomness across space and time. A regulatory focus on only the very worst offenders implies that facilities that can easily and inexpensively comply in a given period may fail to do so (Shimshack and Ward 2010). This insight is broadly consistent with a tax compliance literature supporting at least some randomness in audit targeting regimes (Andreoni et al. 1998; Alm and McKee 2004).

Despite lessons that environmental enforcement activity gets results and that the deterrence effects that emerge from the rational actor paradigm explain significant portions of polluting behavior, a final and persuasive lesson from the literature is that compliance is motivated by many complex factors simultaneously. For example, OSHA interventions do not appear to be the dominant compliance motivation in occupational safety settings. Similarly, the expected utility model significantly underestimates observed tax compliance. Qualitative surveys, especially of small businesses and individuals, suggest that environmental behavior is very strongly influenced by motivations that go well beyond rational calculations of expected benefits and expected penalties.

One factor largely outside the economics of crime paradigm that appears to importantly influence environmental behavior is social pressure. Pressures related to supply chains, consumers, and activists appear to be particularly influential. Emerging evidence suggests that information disclosure, voluntary, or cooperative programs designed to spur such pressures in order to complement traditional enforcement may be especially effective and cost effective. For example, Foulon et al. (2002) found a significant reduction in subsequent pollution after the environmental regulator in British Columbia publicized firms' noncompliance with formal requirements. Thornton et al. (2005) found that 42 percent of surveyed environmental managers 
recognized specific enforcement cases discussed in EPA press releases over the past year or two. Bennear and Olmstead (2008) found that consumer reports of compliance with Safe Drinking Water Act regulations reduced treated facilities' health violations. Innes and Sam (2008) found that a toxic pollution program coupling voluntary programs with traditional enforcement significantly reduced emissions. On a strong cautionary note, however, widespread evidence indicates that information disclosure, voluntary, or cooperative programs designed to spur social pressures cannot by themselves substitute for traditional enforcement policies; that is, the most effective policies may both leverage social pressures and include inspections and enforcement actions (Shimshack 2013; Lyon and Maxwell 2012; Koehler 2007; Harrison 1995). Also, as discussed earlier, the impact of public disclosure on tax compliance remains unresolved.

Normative factors, social interactions, and other socio-behavioral factors also importantly influence environmental performance and compliance. Implications follow. Regulators should apply monitoring and enforcement fairly, promptly, and transparently. Egregious violators should be punished, and amnesty or leniency programs for highly visible violations should be avoided. Agencies should help regulated entities understand the benefits of environmental performance for employees, local communities, and broader economic welfare. Authorities should publicize and reward compliance, and they should endeavor to promote a culture where good behavior is the norm. Facilities, and especially small businesses and individuals, should be reminded that complying is the 'right thing to do.' Rules should be standardized and simplified, and regulators should regularly provide services and compliance assistance.

\section{Conclusion}

We conclude that traditional environmental monitoring and enforcement actions generate important deterrence effects. However, there are limits to such deterrence, and deterrence itself cannot explain all patterns of environmental behavior. Encouraging compliance requires both traditional tools and additional tools. Additional tools may include information disclosure and programs that leverage social norms and social pressures.

Despite many important lessons, we still have much to learn about monitoring, enforcement, and environmental compliance. We do not have a consistent understanding of the social efficiency of monitoring and enforcement actions, as pollution compliance benefits and intervention costs are difficult to measure and remain poorly understood. We have an especially poor understanding of the benefits and costs of alternatives to traditional monitoring and enforcement instruments. We do not yet know how well the most consistent lessons from the existing environmental compliance literature, which draw most insights from air, water, and waste regulation of large industrial point sources, apply to smaller facilities and more recent contaminants of concern (including greenhouse gases). We do not know when lessons from other contexts like tax and occupational compliance settings may be especially compelling - or especially inappropriate - in 
pollution contexts. Environmental deterrence research in international, and especially in developing and transitional country, contexts is limited. ${ }^{24}$ There is still much work to be done.

${ }^{24}$ Dasgupta et al. (2001), Lo et al. (2009), and Duflo (2013) are a few of the notable exceptions. 


\section{References}

Alberini, A. and D.H. Austin (1999), 'Strict liability as a deterrent in toxic waste management: Empirical evidence from accident and spill data.' Journal of Environmental Economics and Management 38: 20-48.

Alberini A. and D. Austin (2002), 'Accidents waiting to happen: liability policy and toxic pollution releases.' Review of Economics and Statistics 84: 729-774.

Allcott, H. (2011), 'Social Norms and Energy Conservation.' Journal of Public Economics 95(910): 1082-1095.

Allingham, M. G. and A. Sandmo (1972), 'Income tax evasion: A theoretical analysis.' Journal of Public Economics 1(3): 323-338.

Alm, J. (1988) 'Uncertain tax policies, individual behavior, and welfare.' The American Economic Review 78(2): 237-245.

Alm, J. (2012), 'Measuring, explaining, and controlling tax evasion: Lessons from theory, experiments, and field studies.' International Tax and Public Finance 19(1): 54-77.

Alm, J. and A. Embaye (2013), "Using dynamic panel methods to estimate shadow economies around the world 1984-2006.' Public Finance Review 41(5): 510-543.

Alm, J., K.M. Bloomquist, and M. McKee (2014a), 'On the external validity of tax compliance experiments.' Economic Inquiry, forthcoming.

Alm, J., K. M. Bloomquist, and M. McKee (2014b), 'When you know your neighbor pays taxes: Information, peer effects, and tax compliance.' Tulane University Working Paper.

Alm, J., B.R. Jackson, and M. McKee (1992), 'Estimating the determinants of taxpayer compliance with experimental data.' National Tax Journal 65(1): 107-114.

Alm, J., B. R. Jackson, and M. McKee. (2009), 'Getting the word out: Increased enforcement, audit information dissemination, and compliance behavior.' Journal of Public Economics 93(34): 392-402.

Alm, J. and M. Yunus (2009), 'Spatiality and persistence in U.S. individual income tax compliance.' National Tax Journal 62(1): 101-124.

Almer, C. and T. Goeschl (2010), 'Environmental crime and punishment: empirical evidence from the German penal code.' Land Economics 86: 707-726.

Almer, C. and T. Goeschl (2013), 'The Sopranos redux: The empirical economics of waste crime.' Regional Studies DOI: 10.1080/00343404.2013.854323. 
Anderson, L.R. and S.L. Stafford (2003), 'Punishment in a regulatory setting: experimental evidence from the VCM.' Journal of Regulatory Economics 24: 91-110.

Andreoni, J., B. Erard, and J. Feinstein (1998), 'Tax compliance.' Journal of Economic Literature 36(2): 818-860.

Ariely, D. (2008), Predictably Irrational: The Hidden Forces That Shape Our Decisions. Harper Collins.

Auffhammer, M. and R.T.Carson (2008), 'Forecasting the path of China's CO2 emissions using province-level information.' Journal of Environmental Economics and Management 55(3): 229247.

Ayres, I. and J. Braithwaite (1992), Responsive Regulation: Transcending the Deregulation Debate. Oxford University Press.

Bartel, A. P. and L.G. Thomas (1985), 'Direct and indirect effects of regulation: A new look at OSHA's impact.' Journal of Law and Economics 28(1): 1-25.

Beatty, T. and J. Shimshack (2010), 'The impact of climate change information: New evidence from the stock market.' The B.E. Journal of Econ. Analysis \& Policy 10(1) (Contributions), Art. 105. Available at: http://www.bepress.com/bejeap/vol10/iss1/art105

Beck, P. J. and W. Jung (1989), 'An economic model of taxpayer compliance under uncertainty.' Journal of Accounting and Public Policy 8: 1-27.

Beck, P. J., J. S. Davis, and W. Jung (1991), 'Experimental evidence on taxpayer reporting behavior.' The Accounting Review 66(3): 535-558.

Becker, G.S (1968), 'Crime and punishment: An economic approach.' Journal of Political Economy 76: 169-217.

Becker, W., H. Buchner, and S. Sleeking (1987), 'The impact of public transfer expenditures on tax evasion: An experimental approach.' Journal of Public Economics 34(2): 243-252.

Bentham, J. (1789), An Introduction to the Principles of Morals and Legislation. Clarendon Press.

Bergman, M. and A. Nevarez (2006), 'Do audits enhance compliance? An empirical assessment of VAT enforcement.' National Tax Journal 59(4): 817-832.

Bressman, L.S. and M.P. Vandenbergh (2006), 'Inside the administrative state: A critical look at the practice of presidential control.' Michigan Law Review 105: 47-99.

Burby, R.J. and R.G. Paterson (1993), 'Improving compliance with state environmental regulations.' Journal of Policy Analysis and Management 12: 753-772. 
Carlough, L. (2004), 'General deterrence of environmental violation: A peek into the mind of the regulated public.' State of Oregon Department of Environmental Quality.

Carslaw, C. APN. (1988), 'Anomalies in income numbers: Evidence of goal oriented behavior.' The Accounting Review 63(2): 321-327.

Chakraborti, L. and J.P. Shimshack (2012), 'The accuracy of self-reported pollution data.' Tulane University Working Paper.

Cohen, M.A. (1987), 'Optimal enforcement strategy to prevent oil spills: An application of a principal-agent model with moral hazard.' Journal of Law and Economics 30: 23-51.

Cohen, M.A. (1992), 'Environmental crime and punishment: legal/economic theory and empirical evidence on enforcement of federal environmental statutes.' Journal of Criminal Law and Criminology 82: 1054-1108.

Cohen, M.A. (1998), 'Monitoring and enforcement of environmental policy.' International Yearbook of Environmental and Resource Economics 3: 44-106.

Congdon, W.J., J.R. Kling, and S. Mullainathan (2011), Policy and Choice - Public Finance through the Lens of Behavioral Economics. The Brookings Institution Press.

Cowell, F. A., and P.F. Gordon (1988). 'Unwillingness to pay: Tax evasion and public good provision.' Journal of Public Economics 36(3): 305-321.

Cronshaw, M. B., and J. Alm (1995), 'Tax compliance with two-sided uncertainty.' Public Finance Quarterly 23(2): 139-166.

Cropper, M. L. and W.E. Oates (1992), 'Environmental economics: A survey.' Journal of Economic Literature 30(2): 675-740.

Dasgupta S, H. Hettige, and D. Wheeler (2000). 'What improves environmental compliance? Evidence from Mexican industry.' Journal of Environmental Economics and Management 39: 39-66.

Dasgupta S, B. Laplante, N. Mamingi, H. Wang (2001) 'Inspections, pollution prices, and environmental performance: Evidence from China.' Ecological Economics 36: 487-498.

De Marchi, S. and J.T. Hamilton (2006), 'Assessing the accuracy of self-reported data: an evaluation of the toxics release inventory.' Journal of Risk and Uncertainty 32(1): 57-76.

Deily, M.E. and W.B. Gray (2007), 'Agency structure and firm culture: OSHA, EPA, and the steel industry.' Journal of Law, Economics, and Organization 23: 685-709.

Delmas, M.A. and M.W. Toffel. (2008), 'Organizational responses to environmental demands: Opening the black box.' Strategic Management Journal 29: 1027-1055. 
Doonan, J, P. Lanoie, and B. Laplante (2005), 'Determinants of environmental performance in the Canadian pulp and paper industry: An assessment from inside the industry.' Ecological Economics 55: 73-84.

Dubin, J. A. (2007), 'Criminal investigation enforcement activities and taxpayer noncompliance.' Public Finance Review 35(4): 500-529.

Dubin, J. A., M. J. Graetz, and L. L. Wilde (1987), 'Are we a nation of tax cheaters? New econometric evidence on tax compliance.' The American Economic Review 77(2): 240-245.

Dubin, J. A., M. J. Graetz, and L. L. Wilde (1990), 'The effect of audit rates on the federal individual income tax 1977-1986.' National Tax Journal 43(4): 395-409.

Dubin, J.A. and L. L. Wilde (1988), 'An empirical analysis of federal income tax auditing and compliance.' National Tax Journal 41(1): 61-74.

Duflo, E., M. Greenstone, R. Pande, and N. Ryan (2013), 'Truth-telling by third-party auditors and the response of polluting firms: Experimental evidence from India'. Quarterly Journal of Economics 128: 1499-1545.

Earnhart, D. (2004a). 'Regulatory factors shaping environmental performance at publicly-owned treatment plants.' Journal of Environmental Economics and Management 48: 655-681.

Earnhart, D. (2004b). 'Panel data analysis of regulatory factors shaping environmental performance.' Review of Economics and Statistics 86: 391-401.

Earnhart, D. and K. Segerson (2012), 'The influence of financial status on the effectiveness of environmental enforcement.' Journal of Public Economics 96: 670-684.

Eckert, H. (2004). 'Inspections, warnings, and compliance: the case of petroleum storage regulation.’ Journal of Environmental Economics and Management 47: 232-259.

Elster, J. (Ed.) (1989), The Cement of Society: A Survey of Social Order. Cambridge University Press.

Epple, D and M. Visscher. (1984), 'Environmental pollution: modeling occurrence, detection, and deterrence.' Journal of Law and Economics 27: 29-60.

Feige, E. L. (1994), 'The underground economy and the currency enigma.' Public Finance/Finances Publiques 49: 119-136.

Fortin, B., G. Lacroix, and M.C. Villeval (2007), 'Tax evasion and social interactions.' Journal of Public Economics 91(11): 2089-2112.

Foulon, J., P. Lanoie, and B. Laplante (2002), 'Incentives for pollution control: regulation or information?'. Journal of Environmental Economics and Management 44: 169-187 
Frey, B. S. and H. Weck-Hannemann (1984), 'The hidden economy as an 'Unobserved' Variable.' European Economic Review 26(1): 33-53.

Friedland, N., S. Maital, and A. Rutenberg (1978), 'A simulation study of income tax evasion.' Journal of Public Economics 10(1): 107-116.

Friesen, L. (2003), 'Targeting enforcement to improve compliance with environmental regulations'. Journal of Environmental Economics and Management 46: 72-85.

Friesen, L. (2012), 'Certainty of punishment versus severity of punishment: An experimental investigation.' Southern Economic Journal 79: 399-421.

Friesen, L. and L. Gangadharan (2013), 'Environmental markets: what do we learn from the lab?' Journal of Economic Surveys 27: 515-535.

Giles, C. (2013), Next Generation Compliance. Environmental Forum. Washington, DC: Environmental Law Institute. Sept-Oct: 22-25.

Glicksman, R.L. and D.H. Earnhart (2007), 'Comparative effectiveness of government interventions on environmental performance in the chemical industry.' Stanford Environmental Law Journal 26: 317.

Graetz, M. J., J.F. Reinganum, and L.L.Wilde. (1986). 'The tax compliance game: Toward an interactive theory of tax enforcement.' Journal of Law, Economics, and Organization 2: 1-32.

Grant, L.E and K. Grooms. (2012), 'Do non-profits encourage compliance? Watershed groups and the US Clean Water Act.' University of Wisconsin-Milwaukee Working Paper.

Grant, L.E. and C. Langpap. (2013), 'Private provision of public goods: Evidence from the effect of environmental groups on water quality.' University of Wisconsin-Milwaukee Working Paper.

Grau, M.V. and T. Groves. (1997, 'The oil spill process: the effect of coast guard monitoring on oil spills.' Environmental Resource Economics 10: 315-339.

Gray, W.B and M.E. Deily (1996), 'Compliance and enforcement: air pollution regulation in the US steel industry.' Journal of Environmental Economics Management 31: 96-111.

Gray, W. B. and J.M. Mendeloff (2005), 'The declining effects of OSHA inspections on manufacturing injuries 1979-1998.' Industrial and Labor Relations Review 58(4): 571-587.

Gray, W. B. and J.T. Scholz (1993), 'Does regulatory enforcement work? A panel analysis of OSHA enforcement.' Law and Society Review 27(1): 177-213.

Gray, W.B. and R.J. Shadbegian. (2005), 'When and why do plants comply? Paper mills in the 1980s.' Law \& Policy 27: 238-261. 
Gray, W.B. and R.J., Shadbegian (2007), 'The environmental performance of polluting plants: A spatial analysis.' Journal of Regional Science 47: 63-84.

Gray, W.B and J.P. Shimshack (2011), 'The effectiveness of environmental monitoring and enforcement: A review of the empirical evidence.' Review of Environmental Economics and Policy 5: 3-24.

Greenberg, J. (1984), 'Avoiding tax avoidance: A (repeated) game-theoretic approach.' Journal of Economic Theory 32: 1-13.

Greenstone, M. (2003), 'Estimating regulation-induced substitution: The effect of the Clean Air Act on water and ground pollution.' The American Economic Review 93(2): 442-448.

Gunningham, N., R.A. Kagan, and D.Thornton (2004), 'Social license and environmental protection: why businesses go beyond compliance.' Law \& Social Inquiry 29(2): 307-341.

Gunningham, N. A., D. Thornton, and R.A. Kagan (2005), 'Motivating management: Corporate compliance in environmental protection.' Law \& Policy 27 (2): 289-316.

Hanna, R.N. and P. Oliva (2010), 'The impact of inspections on plant-level air emissions.' The BE Journal of Economic Analysis and Policy 10: 1-31.

Harford, J.D. (1991), 'Measurement error and state-dependent pollution control enforcement.' Journal of Environmental Economics and Management 21: 67-81.

Harford, J.D. (1993), 'Improving on the steady state in the state-dependent enforcement of pollution control.' Journal of Environmental Economics and Management 24: 133-138.

Harford, J.D. and W. Harrington (1991), 'A reconsideration of enforcement leverage when penalties are restricted.' Journal of Public Economics 45: 391-395.

Harrington, W. (1988), 'Enforcement leverage when penalties are restricted.' Journal of Public Economics 37: 29-53.

Harrison, G. W. and J.A. List (2004), 'Field experiments.' Journal of Economic Literature 42(4): 1009-1055.

Harrison, K. (1995), 'Is cooperation the answer? Canadian environmental enforcement in comparative context.' Journal of Policy Analysis and Management 14: 221-244.

Hasegawa, M., J. Hoopes, R. Ishida, and J. Slemrod (2012), 'The effect of public disclosure on reported taxable income: Evidence from individuals and corporations in Japan.' National Bureau of Economic Research Working Paper.

Haviland, A., R. Burns, W. Gray, T. Ruder, T., and J. Mendeloff (2010), 'What kinds of injuries do OSHA inspections prevent?' Journal of Safety Research 41(4): 339-345. 
Haviland, A., R. Burns, W. Gray, T. Ruder, T., and J. Mendeloff (2012), 'A new estimate of the impact of OSHA inspections on manufacturing injury rates, 1998-2005.' American Journal of Industrial Medicine 55(11): 964-975.

Helland, E. (1998), 'The enforcement of pollution control laws: Inspections, violations, and selfreporting.' Review of Economics and Statistics 80(1): 141-153.

Henderson, J.V., A. Storeygard, and D. Weil (2009), 'Measuring economic growth from outer space (No. w15199).' National Bureau of Economic Research Working Paper.

Heyes, A. (2000), 'Implementing environmental regulation: enforcement and compliance.' Journal of Regulatory Economics 17: 107-129.

Heyes, A. and N. Rickman (1999), 'Regulatory dealing-revisiting the Harrington paradox.' Journal of Public Economics 72: 361-378.

Innes, R. (1999), 'Remediation and self-reporting in optimal law enforcement.' Journal of Public Economics 72: 379-393.

Innes, R. (1999), 'Self-policing and optimal law enforcement when violator remediation is valuable.' Journal of Political Economy 107: 1305-1325

Innes, R. (2001), 'Violator avoidance activities and self-reporting in optimal law enforcement.' Journal of Law, Economics, and Organization 17: 239-256.

Innes, R. and A.G. Sam (2008), 'Voluntary pollution reductions and the enforcement of environmental law: An empirical study of the 33/50 program.' Journal of Law and Economics 51: 271-296.

Iyer, G. S., P. M. J. Reckers, and D. L. Sanders (2010), ' Increasing tax compliance in Washington State: A field experiment.' National Tax Journal 63(1): 7-32.

Jaffe, A. B., S. Peterson, P. Portney, and R.N. Stavins (1995), 'Environmental regulation and the competitiveness of US manufacturing: what does the evidence tell us?' Journal of Economic Literature 33(1): 132-163.

Kagan, R. A., N. Gunningham, and D. Thornton (2011), 'Fear, duty, and regulatory compliance: lessons from three research projects.' In Explaining compliance: business responses to regulation. Edward Elgar Publishing, 37-58.

Kagan, R. A., N. Gunningham, and D. Thornton (2003), 'Explaining corporate environmental performance: How does regulation matter?' Law and Society Review 37: 51-90.

Kahneman, D. (2003), 'Maps of bounded rationality: Psychology for behavioral economics.' The American Economic Review 93(5): 1449-1475. 
Kaplow, L. and S. Shavell (1994), 'Optimal law enforcement with self-reporting of behavior.' Journal of Political Economy 102: 583-606.

Keohane, N., E. Mansur, and A. Voynov (2009), 'Averting regulatory enforcement: Evidence from new source review.' Journal of Economics and Management Strategy 18: 75-104.

Khanna, M. and W. Anton (2002), 'What is driving corporate environmentalism: Opportunity or threat?' Corporate Environmental Strategy 9(4): 409-417.

Khanna, M., W. Quimio, and D. Bojilova (1998), 'Toxic release information: A policy tool for environmental information.' Journal of Environmental Economics and Management 36: 243-66.

Kirchler, E. (2007), The Economic Psychology of Tax Behavior. Cambridge University Press.

Kitzmueller, M. and J. Shimshack (2012), 'Economic perspectives on corporate social responsibility.' Journal of Economic Literature 50(1): 51-84.

Klassen, R.D. and C. McLaughlin (1996), 'The impact of environmental management on firm performance.' Management Science 42: 1199-1214.

Kleven, H., M. B. Knudsen, K. T. Kreiner, S. Pedersen, and E. Saez (2011), 'Unwilling or unable to cheat? Evidence from a randomized tax audit experiment in Denmark.' Econometrica 79(3): 651-692.

Koehler, D. A. (2007), 'The effectiveness of voluntary environmental programs-A policy at a crossroads?’ Policy Studies Journal 35(4), 689-722.

Konar S. and M. Cohen (1996), 'Information as regulation: The effect of community right to know laws on toxic emissions.' Journal of Environmental Economics and Management 32, 10924

Landsberger, M. and I. Meilijson (1982), 'Incentive generating state dependent penalty system: The case of income tax evasion.' Journal of Public Economics 19: 333-352.

Langpap, C. and J. Shimshack (2010), 'Private citizen suits and public enforcement: Substitutes or complements?' Journal of Environmental Economics and Management 59: 235-249.

Laplante, B. and P. Rilstone (1996), 'Environmental inspections and emissions of the pulp and paper industry in Quebec.' Journal of Environmental Economics and Management 31: 19-36.

Leeth, J. D. (2012), 'OSHA's role in promoting occupational safety and health.' Foundations and Trends in Microeconomics 7(4): 267-353.

Levine, D. I., M.W. Toffel, and M.S. Johnson (2012), 'Randomized government safety inspections reduce worker injuries with no detectable job loss.' Science 336(6083): 907-911. 
Levitt, S.D and J.A. List (2007), 'What do laboratory experiments measuring social preferences reveal about the real world?' Journal of Economic Perspectives 21(2): 153-174.

Livernois, J. and C.J. McKenna (1999), 'Truth or consequences: Enforcing pollution standards with self-reporting.' Journal of Public Economics 71: 415-440.

Lo, C., G. Fryxell, B. van Rooij (2009), 'Changes in enforcement styles among environmental enforcement officials in China.' Environment and Planning A 41: 2706-2723.

Lyon, T. and J. Maxwell (2000), 'Voluntary approaches to environmental regulation: A survey.' In Economic Institutions and Environmental Policy, Maurizio Franzini and Antonio Nicita, Eds, 142-174.

Lyon, T. and J. Shimshack (2012), 'Environmental Disclosure: Evidence From Newsweek's Green Companies Rankings.’ Business \& Society, 0007650312439701.

Magat, W.A. and W.K. Viscusi (1990), 'Effectiveness of the EPA's regulatory enforcement: The case of industrial effluent standards.' Journal of Law and Economics 33: 331-360.

Malik, A (1993), 'Self-reporting and the design of policies for regulating stochastic pollution.' Journal of Environmental Economics and Management 24: 241-257.

May, P. (2005), 'Regulation and compliance motivations: examining different approaches.' Public Administration Review 65: 31-44.

May, P. and S. Winter (2001), 'Reconsidering styles of regulatory enforcement: Patterns in Danish agro-environmental inspection.' Law and Policy 22:143-173.

Mendeloff, J. and W. Gray (2005), 'Inside the black box: How do OSHA inspections lead to reductions in workplace injuries?' Law and Policy 27(2): 219-237.

Mintz, J. (2012), 'Enforcement at the EPA: high stakes and hard choices.' Austin, TX: University of Texas Press (revised edition).

Myles, G. D., and R.A. Naylor (1996), 'A model of tax evasion with group conformity and social customs.' European Journal of Political Economy 12(1): 49-66.

Nadeau, L. (1997), 'EPA effectiveness at reducing the duration of plant-level noncompliance.' Journal of Environmental Economics and Management 34: 54-78.

Naysnerski, W. and T. Tietenberg (1992), 'Private enforcement of federal environmental law.' Land Economics 68: 28-48.

Pfaff, A. and C. Sanchirico (2004), 'Big field, small potatoes: An empirical assessment of EPA's self-audit policy.' Journal of Policy Analysis and Management 23(3): 415-432. 
Plumley, A. (1996), 'The determinants of individual income tax compliance: Estimating the impacts of tax policy, enforcement, and IRS responsiveness.' Internal Revenue Service, Publication 1916 (Rev. 11-96). Washington, D.C.

Polinsky, A. and S. Shavell (2000), 'The economic theory of public enforcement of law.' Journal of Economic Literature 38: 45-76.

Pomeranz, D. (2013), 'No taxation without information: Deterrence and self-enforcement in the value added tax (No. w19199).' National Bureau of Economic Research Working Paper.

Porter, M. E., and C. Van der Linde (1995), 'Toward a new conception of the environmentcompetitiveness relationship.' Journal of Economic Perspectives 9(4): 97-118.

Reinganum, J. and L. Wilde (1985), 'Income tax compliance in a principal-agent framework.' Journal of Public Economics 26: 1-18.

Reinganum, J. and L. Wilde (1986), 'Equilibrium verification and reporting policies in a model of tax compliance.' International Economic Review 27: 739-760.

Ruhm, C. and C. Borkoski (2003), 'Compensation in the nonprofit sector.' Journal of Human Resources 38(4): 992-1021.

Ruser, J. and R. Butler (2010), 'The economics of occupational safety and health.' Foundations and Trends in Microeconomics 5.5: 301-354.

Ruser, J. and R. Smith (1991), 'Reestimating OSHA's effects: Have the data changed?' Journal of Human Resources 26(2): 212-235.

Russell, C., W. Harrington, and W. Vaughan (1986), Enforcing Pollution Control Laws. Resources for the Future, Washington, DC.

Sah, R. K. (1991), 'Social osmosis and patterns of crime.' Journal of Political Economy 99(6): 1272-1295.

Sanchez, I., and J. Sobel (1993), 'Hierarchical design and enforcement of income tax policies.' Journal of Public Economics 50: 345-369.

Schneider, F. (2005), 'Shadow economies around the world: What do we really know?' European Journal of Political Economy 21: 598-642.

Schneider, F. and D. Enste (2000), 'Shadow economies: Size, causes, and consequences.' Journal of Economic Literature 38: 77-114.

Schneider, F. and D. Enste (2002), The Shadow Economy: An International Survey. Cambridge University Press. 
Scholz, J. T., and W.B. Gray (1990), 'OSHA enforcement and workplace injuries: A behavioral approach to risk assessment.' Journal of Risk and Uncertainty 3(3): 283-305.

Scholz, J.T. (1984), 'Voluntary compliance and regulatory enforcement.' Law and Policy 6: 385404.

Scotchmer, S. and J. Slemrod (1989), 'Randomness in tax enforcement.' Journal of Public Economics 38: 17-32.

Shavell, S. (2004), Foundations of Economic Analysis of Law. Harvard University Press.

Shimshack, J. (2009), 'Pilot Comparative Analysis of Monitoring and Enforcement Impact Measures' State-of-Science White Paper Prepared for the Environmental Protection Agency's Office of Enforcement and Compliance Assurance. June 2009.

Shimshack, J. (2013), 'Information programs.' Encyclopedia of Energy, Natural Resource, and Environmental Economics. J. Shogren, Ed. Elsevier Science Publishers. April 5, 2013.

Shimshack, J. (2014), 'The economics of environmental monitoring and enforcement: A review.' Annual Review of Resource Economics, forthcoming.

Shimshack J. and M.B. Ward (2005), 'Regulator reputation, enforcement, and environmental compliance.' Journal of Environmental Economics and Management 50: 519-540.

Shimshack J. and M.B. Ward (2008), 'Enforcement and over-compliance.' Journal of Environmental Economics and Management 55: 90-105.

Shimshack, J. and M.B. Ward (2010), 'Repeat offenders, enforcement, and environmental compliance.' Tulane University Working Paper.

Slemrod, J., M. Blumenthal, and C. Christian (2001), 'Taxpayer response to an increased probability of audit: Evidence from a controlled experiment in Minnesota.' Journal of Public Economics 79(3): 455-483.

Slemrod, J., T.O. Thoresen, and E.E. Bø (2013), 'Taxes on the internet: Deterrence effects of public disclosure.' CESifoWorking Paper.

Simpson, S. S., C. Gibbs, M. Rorie, L. Slocum, M. Cohen, and M. Vandenbergh, (2013), 'An empirical assessment of corporate environmental crime-control strategies.' The Journal of Criminal Law \& Criminology 103(1): 231-278.

Smith, K. M. (2004), 'Who's suing whom: A comparison of government and citizen suit environmental enforcement actions brought under EPA-administered statutes, 1995-2000.' Columbia Journal of Environmental Law 29: 359-413. 
Smith, R. S. (1979), 'The impact of OSHA inspections on manufacturing injury rates.' Journal of Human Resources 14(2):145-170.

Spence, D.B. (2001), 'The shadow of the rational polluter: rethinking the role of rational actor models in environmental law.' California Law Review 89: 917-998.

Stafford, S. (2002), 'The effect of punishment on firm compliance with hazardous waste regulations.' Journal of Environmental Economics and Management 44: 290-308.

Stafford, S. (2003), 'Assessing the effectiveness of state regulation and enforcement of hazardous waste.' Journal of Regulatory Economics 23: 27-41.

Stafford, S. (2006), 'Rational or confused polluters? Evidence from hazardous waste compliance.' BE Journals of Economic Analysis and Policy 5: 1-31.

Stafford, S. (2014), 'Will additional federal enforcement improve the performance of pipelines in the US?' International Review of Law and Economic 37: 137-146.

Stranlund, J. (2013), 'A brief review of the economics of enforcing environmental policies.' Encyclopedia of Energy, Natural Resource, and Environmental Economics. Elsevier Science Publishers.

Telle, K. (2013), 'Monitoring and enforcement of environmental regulations: Lessons from a natural field experiment in Norway.' Journal of Public Economics 99: 24-34.

Thompson, B. (2000), 'Continuing innovations of citizen enforcement.' Utah Law Review 185: 185-236.

Thornton D., N. Gunningham, and R. Kagan (2005), 'General deterrence and corporate environmental behavior.' Law and Policy 27: 262-288.

Toffel, M. and J. Short (2011), 'Coming clean and cleaning up: does voluntary self-reporting indicate effective self-policing?' Journal of Law and Economics 54: 609-649.

Torgler, B.. (2007), Tax Compliance and Tax Morale: A Theoretical and Empirical Analysis. Edward Elgar Publishing.

Tyler, T. R. (1990), Why People Obey the Law. Princeton University Press.

Uhlmann, D. (2009), 'Environmental crime comes of age: The evolution of criminal enforcement in the environmental regulatory scheme.' Utah Law Review 4: 1223-1252.

Viscusi, W. K. (1979), 'The impact of occupational safety and health regulation.' The Bell Journal of Economics 10(1): 117-140. 
Viscusi, W. K. (1986), 'The impact of occupational safety and health regulation, 1973-1983.' The RAND Journal of Economics 17(4): 567-580.

Webley, P., P. Robben, H. Elffers, and D. Hessing (1991), Tax Evasion: An Experimental Approach. Cambridge University Press.

Winter, S. and P. May P (2001), 'Motivation for compliance with environmental regulations.' Journal of Policy Analysis and Management 20(4): 675-698.

Witte, A. and D. Woodbury (1985), 'The effect of tax laws and tax administration on tax compliance: The case of the U.S. individual income tax.' National Tax Journal 38(1): 1-13.

U.S. Census Bureau, (2008), Pollution Abatement Costs and Expenditures. Washington, DC.

U.S. Environmental Protection Agency (1989), The Enforcement Management System: National Pollutant Discharge Elimination System. Washington, DC.

U.S. Environmental Protection Agency (2001), Enforcement Policy for Section 112(r) of the Clean Air Act. Washington, DC.

U.S. Environmental Protection Agency (2009), National Water Quality Inventory: Report to Congress, 2004 Reporting Cycle. EPA-841/R-08-001. Washington, DC.

U.S. Environmental Protection Agency (2012), Our Nation's Air: Status and Trends through 2010. EPA-454/R-12-001. Washington, DC.

U.S. Environmental Protection Agency (2014), 'Fiscal Year 2014-2018 EPA Strategic Plan.' Washington, DC.

U.S. Internal Revenue Service (2012), 'Federal tax compliance research: Tax year 2006 tax gap estimation.' Washington, DC. 